\title{
A Supramolecular View on the Cooperative Role of Brønsted and Lewis Acid Sites in Zeolites for Methanol Conversion
}

Simon Bailleul, ${ }^{\dagger}$ Irina Yarulina, ${ }^{\ddagger}$ Alexander E. J. Hoffman, ${ }^{\dagger}$ Abhay Dokania, ${ }^{\ddagger}$ Edy Abou-Hamad, ${ }^{\S}$ Abhishek Dutta Chowdhury, ${ }^{\ddagger}$ Giovanni Pieters, ${ }^{\dagger}$ Julianna Hajek, ${ }^{\dagger}$ Kristof De Wispelaere, ${ }^{\dagger}$ Michel Waroquier, ${ }^{\dagger}$ Jorge Gascon, ${ }^{*}+\infty$ and Veronique Van Speybroeck ${ }^{*},{ }^{\dagger}$

${ }^{\dagger}$ Center for Molecular Modeling (CMM), Ghent University, Technologiepark 46, B-9052 Zwijnaarde, Belgium

${ }^{\ddagger}$ King Abdullah University of Science and Technology, KAUST Catalysis Center, Advanced Catalytic Materials, Thuwal 23955-6900, Saudi Arabia

${ }^{\S}$ King Abdullah University of Science and Technology (KAUST), Core Laboratories, Thuwal, Saudi Arabia

Supporting Information

ABSTRACT: A systematic molecular level and spectroscopic investigation is presented to show the cooperative role of Brønsted acid and Lewis acid sites in zeolites for the conversion of methanol. Extra-framework alkaline-earth metal containing species and aluminum species decrease the number of Brønsted acid sites, as protonated metal clusters are formed. A combined experimental and theoretical effort shows that postsynthetically modified ZSM-5 zeolites, by incorporation of extra-framework alkaline-earth metals or by demetalation with dealuminating agents, contain both mononuclear $[\mathrm{MOH}]^{+}$and double protonated binuclear metal clusters $\left[\mathrm{M}(\mu-\mathrm{OH})_{2} \mathrm{M}\right]^{2+}(\mathrm{M}=\mathrm{Mg}, \mathrm{Ca}, \mathrm{Sr}, \mathrm{Ba}$, and $\mathrm{HOAl})$. The metal in the extra-framework clusters has a Lewis acid character, which is confirmed experimentally and theoretically by IR spectra of adsorbed pyridine. The strength of the Lewis acid sites $(\mathrm{Mg}>\mathrm{Ca}$ $>\mathrm{Sr}>\mathrm{Ba}$ ) was characterized by a blue shift of characteristic IR peaks, thus offering a tool to sample Lewis acidity experimentally. The incorporation of extra-framework Lewis acid sites has a substantial influence on the reactivity of propene and benzene methylations. Alkaline-earth Lewis acid sites yield increased benzene methylation barriers and destabilization of typical aromatic intermediates, whereas propene methylation routes are less affected. The effect on the catalytic function is especially induced by the double protonated binuclear species. Overall, the extra-framework metal clusters have a dual effect on the catalytic function. By reducing the number of Brønsted acid sites and suppressing typical catalytic reactions in which aromatics are involved, an optimal propene selectivity and increased lifetime for methanol conversion over zeolites is obtained. The combined experimental and theoretical approach gives a unique insight into the nature of the supramolecular zeolite catalyst for methanol conversion which can be meticulously tuned by subtle interplay of Brønsted and Lewis acid sites.

\section{INTRODUCTION}

To shift the global energy and chemicals economy from petroleum-based to more sustainable resources, highly efficient catalysts are needed. While innovative electro- and photocatalysis processes are being developed, there is a major window of opportunities for the optimization and design of thermal zeolite-catalyzed processes which are widely applied in the (petro)chemical industry. ${ }^{1}$ Zeolites have been widely studied from an experimental and molecular simulations viewpoint, $^{2,3}$ and are a very stable and versatile class of materials. Many contemporary processes focus on nonconventional feedstocks containing heteroatoms, for which meticulous design of active sites in zeolites is of primary importance to ensure selective and efficient conversion. ${ }^{4-7}$

In this view, methanol-to-olefins (MTO) conversion over zeolite catalysts received much attention in recent decades, as it has proven to be a successful technology to bypass crude oil in the production of highly demanded light olefins, namely ethene and propene. ${ }^{8-11}$ The reaction mechanism governing this process has been up for discussion for many years, and it is now generally accepted that instead of a direct $\mathrm{C}-\mathrm{C}$ coupling between reactant molecules, a hydrocarbon pool (HP) consisting of aromatic or aliphatic molecules cocatalyzes the reactions leading to olefin production (Figure 1a). ${ }^{12-14}$ According to the seminal work of Haw and co-workers ${ }^{15}$ an active MTO catalyst should be regarded as a supramolecular assembly consisting of the zeolite channel system decorated with Brønsted acidic functions in which organic compounds need to be present to generate an active catalyst. Furthermore,

Received: July 14, 2019

Published: August 29, 2019 


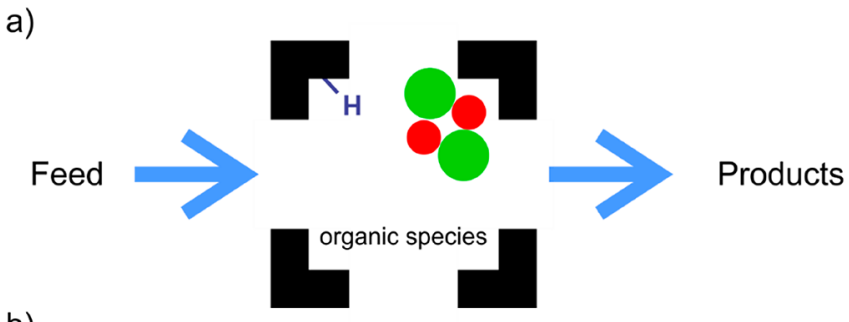

b)

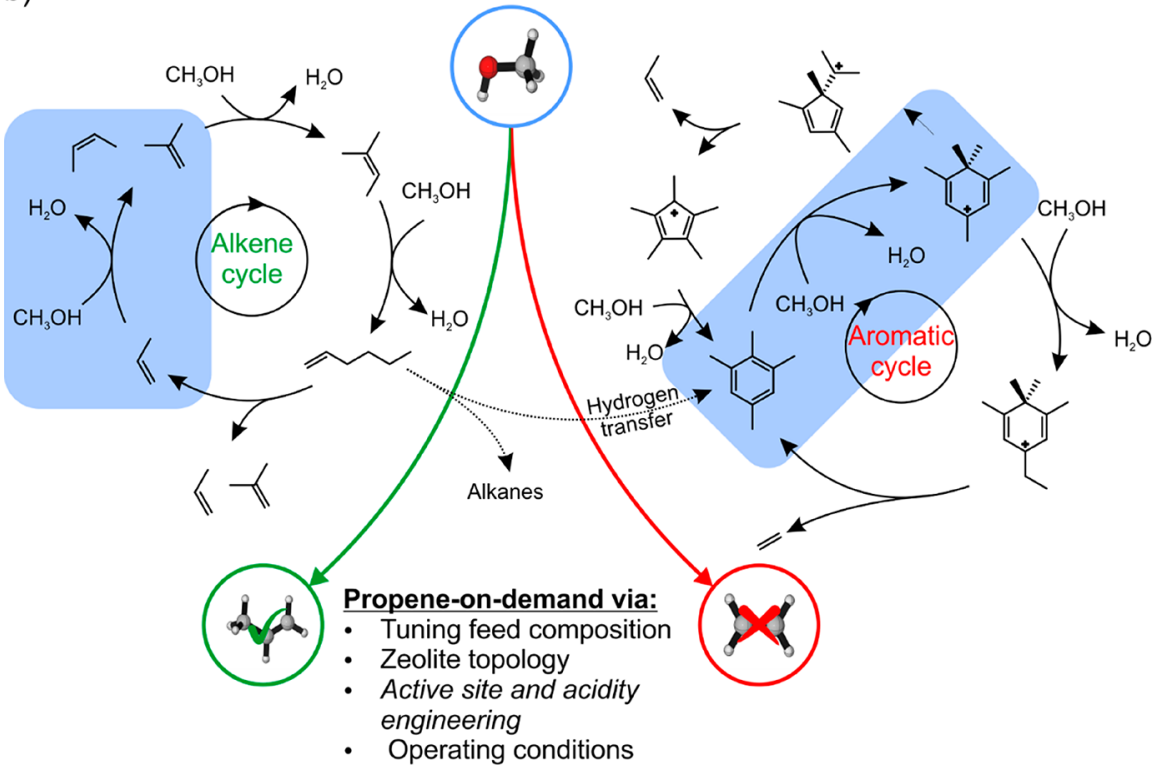

Figure 1. (a) Schematic representation of the zeolite supramolecular catalyst according to the view of Haw et al. ${ }^{15}$ on the MTO process. (b) Schematic representation of the MTO process as solution for the disparity between propene production and demand using the dual cycle concept, which consists of the alkene and aromatic cycle. In both mechanisms, the importance of methylation reactions as initiating steps is indicated in blue. Propene selectivity can be increased by suppressing the aromatic cycle by tuning the feed composition, adapting the zeolite topology, engineering the active site, or optimizing the process. The focus of this article is on the engineering of the active site. ${ }^{42}$

the supramolecular system could be modified with some inorganic compound to further tune the catalytic function (Figure 1a). However, this option has to date only been explored to a more limited extent. ${ }^{16-30}$

A rational catalyst design to control olefin selectivity and resistance to coking requires intimate insight into the operating catalytic cycles. For the MTO process, there is current consensus that the HP mechanism (depicted in Figure 1b) consists of two interacting reaction cycles, namely the alkene and aromatic cycle, which is also referred to as the dual cycle concept. $^{3,8,10,31,32}$ In both reaction cycles, methylation reactions (indicated in blue in Figure 1) are key reactions and have been widely studied in the framework of MTO catalysis. $^{33-41}$

According to the seminal work of Svelle and co-workers ${ }^{32}$ on the dual cycle mechanism, the formation of ethene is mechanistically separated from the formation of propene. Ethene is supposed to be mainly formed via the aromatic cycle, whereas propene and higher olefins are formed via the alkene cycle which consists of alkene cracking reactions and methylations. This characteristic makes MTO conversion especially interesting as a propene-on-demand process as a solution for the increasing disparity between the propene production and demand. ${ }^{4-46}$ Based on this knowledge, various strategies have been tested such as tuning the feed composition, $^{47}$ the zeolite topology, ${ }^{8,10}$ acidity, ${ }^{24,25}$ and operating conditions to increase the selectivity to propene by promoting the alkene cycle over the aromatic cycle. Hereafter some examples are given which illustrate the wide options that have been explored so far. Promotion of one of the reaction cycles can be obtained via cofeeding of the hydrocarbon pool species aiding in the promoted cycle. Experimental studies over SAPO-34 and ZSM-5 showed that cofeeding olefins does not have an influence on the selectivity, while cofeeding aromatics led to enhanced methane and ethene formation, suggesting aromatic cycle promotion. ${ }^{12,13,47}$ A second possibility is to suppress a reaction cycle by conveniently selecting the catalyst topology, as was done in the study of the MTO process over H-ZSM-22 by Teketel et al., ${ }^{48,49}$ where they showed that the aromatic cycle was suppressed via shape selectivity due to the confined space in the 1D 10-ring channels of the TON topology. In CHA structured materials on the other hand, the aromatic cycle dominates product formation due to high concentrations of aromatics that cannot diffuse through the narrow windows of CHA cages. ${ }^{36,50}$ In ZSM-5 (MFI) both cycles typically operate simultaneously. ${ }^{32}$ Furthermore, the aromatic cycle can be suppressed by lowering the acid strength of the Brønsted acid sites (BASs) as shown for the AFI structured H-SAPO-5 and H-SSZ-24 materials. Even when cofeeding benzene, the alkene cycle was found to dominate under MTO conditions in the weaker acidic H-SAPO-5 material. ${ }^{51-53}$ Also the reaction conditions may substantially impact the product selectivity as was shown by the group of Iglesia where they promoted the alkene cycle in the large pore zeolite H-BEA, characterized by the aromatic cycle, ${ }^{54-57}$ by utilization of low temperatures $(453-493 \mathrm{~K})$ and high 
pressures $(60-250 \mathrm{kPa}){ }^{58,59}$ Another example of adapting the process conditions to increase propene selectivity can be found in the Lurgi methanol-to-propylene (MTP) process (around atmospheric pressure and $733-753 \mathrm{~K}$ ), where they increase propene selectivity using high siliceous H-ZSM-5 and undesired product recycles. ${ }^{10,60}$

Referring back to the initial supramolecular concept of the MTO catalyst, an alternative strategy to increase propene selectivity and catalyst lifetime is active site engineering by incorporation of extra-framework species in the MTO catalyst. Inorganic modification of the zeolite was explored using phosphorus, ${ }^{16-18}$ boron, ${ }^{19}$ transition metal, ${ }^{20-23,61,62}$ and alkaline earth metals. ${ }^{24-30}$ Such modifications typically reduce the Brønsted acid site density, which can also be achieved by tuning the $\mathrm{Si} / \mathrm{Al}$ ratio in the zeolite synthesis stage or by postsynthetic dealumination. ${ }^{25,63-65}$ As aromatics formation typically requires vicinal BASs, ${ }^{21}$ many zeolite modifications reduce aromatics formation and increase the importance of the alkene cycle by creating isolated BASs. ${ }^{66-70}$ Additionally, these modifications can exhibit catalytic activity themselves, as they are known to create Lewis acid sites (LASs). ${ }^{24,25,71}$

In this work, we further build on the concept of inorganic modification of the zeolite supramolecular MTO catalyst, by studying the influence of extra-framework metal containing cationic clusters on the selectivity toward the alkene or aromatic cycle. Inspired by the recent work of Yarulina et al. $^{24,25}$ where a 2 -fold increase in propene selectivity and a nine times longer catalyst lifetime was obtained by $\mathrm{Ca}$ modification of ZSM-5, a set of alkaline-earth metal $(\mathrm{Mg}, \mathrm{Ca}, \mathrm{Sr}$, and $\mathrm{Ba})$ clusters are considered. Some earlier studies explored the beneficial effect of alkaline-earth metal incorporation in ZSM-5 on the methanol-to-olefin process, but did not receive so much attention at that time since propene was not the product of interest. ${ }^{26-30,71}$ Yarulina et al. ascribed the enhanced performance of Ca-ZSM-5 for MTO to the reduction of the Brønsted acid site density and introduction of Lewis acid sites. ${ }^{24}$ Such modification of the catalyst would suppress the aromatic cycle. $^{25}$ Additionally, dealumination of zeolites is known to lead to formation of both mesopores and extra-framework aluminum (EFAl) species, which exhibit a Lewis acid nature. ${ }^{65,72-74}$ This postsynthetic modification is also known to increase propene selectivity and catalyst lifetime. ${ }^{69,75,76}$

For both alkaline-earth metal modifications and EFAl species, the nature and role of LASs on the zeolite supramolecular function for the methanol conversion will be investigated. Although some theoretical insights on the effect of Lewis acid sites on methanol conversion were already obtained, a systematic spectroscopic, energetic, and reactivity study at the molecular level is not available for metal containing clusters. Therefore, we aim at filling this void by performing a combined theoretical-experimental screening of several modified Lewis acid sites in zeolites to get molecular insights into their specific nature and role under MTO conditions. The series of extra-framework incorporated metal clusters are expected to have distinct differences in acidic strength, which may impact the stability and reactivity pattern of the supramolecular catalyst. In principle various multinuclear cationic complexes containing bridging $\mathrm{O}$ or $\mathrm{OH}$ ligands may be formed. The structure of these species will be assessed from an energetic and spectroscopic assessment, including solid state NMR. We aim to unravel the structure of the extra-framework species in the zeolite pores, the chemical nature of the modified active site, and how the modified active site affects the reactivity and relative importance of the alkene and aromatic cycle in the MTO process. Based on this systematic screening of Lewis acidity in zeolite pores, better design rules with complex active sites may be proposed for next generation MTO catalysts.

\section{MATERIALS AND METHODS}

2.1. Computational Details. To unravel the nature of the active site and its reactivity toward methylations, both static and dynamic approaches based on the Density Functional Theory (DFT) methodology are used.

Static periodic DFT calculations have been performed using the Vienna Ab Initio Simulations Package (VASP 5.4) to analyze the structure and nature of the active site, the methylation of propene, benzene, pseudocumene, and durene, and to calculate the protonation energies of the aromatics. ${ }^{7-80}$ The unit cell of ZSM-5 used during these static simulations consists of $96 \mathrm{~T}$ atoms with the cell parameters being: $a=20.02 \AA, b=20.25 \AA, c=13.49 \AA, \alpha=89.87^{\circ}, \beta$ $=89.69^{\circ}$, and $\gamma=90.10^{\circ}$. More information on the unit cell and the performed $\mathrm{Al}$ substitutions for charge compensation can be found in the Supporting Information (SI), Section 1. For the DFT calculations, the PBE functional with Grimme D3 dispersion corrections are used. $^{81,82}$ This functional gives a reasonable compromise between accuracy and computational cost. ${ }^{83}$ Other methodologies aiming at reaching chemical accuracy are far more computational expensive and beyond reach for the current study. ${ }^{84,85}$ Nevertheless, a benchmark study on the influence of the functional and dispersion correction scheme on the methylation of propene and benzene is performed and the results are discussed in detail in Section 1.5 of the SI. These results show that the choice of functional and dispersion scheme keeps the general trend of features observed when studying differences of energies. The PBE-D3 functional turns out to follow the average behavior of the 12 various LOTs which have been considered. This methodology is further retained in the remainder of the paper to determine in a qualitative way the effects of postmodification of the catalyst. Due to the huge amount of calculations performed within this study, hierarchical cluster approaches relying on high level wave function based methods are beyond the scope for the current study. ${ }^{84,86-90}$ Furthermore, the projector augmented wave (PAW) method, a plane-wave cutoff of $600 \mathrm{eV}$, and a self-consistent field (SCF) convergence criterion of $10^{-5} \mathrm{eV}$ are used. $^{91,92}$ During the VASP calculations, the Brillouin zone is restricted to the $\Gamma$-point. Transition states are initially optimized with the improved dimer method of Heyden et al. ${ }^{93}$ and then refined with a quasi-Newton algorithm as implemented in VASP. ${ }^{94}$ Geometries are slightly displaced along the normal mode corresponding to the motion that leads the system over the barrier to generate starting geometries for the optimization of reactant and product states. For these calculations, a conjugate gradient algorithm is applied. ${ }^{95}$

Since partial Hessian vibrational analysis (PHVA) is shown to be an attractive alternative for computationally demanding full Hessian calculations (FHVA) for entropy calculations, this scheme is used for the normal-mode analysis (NMA) in this work using TAMkin. ${ }^{96,97}$ In a PHVA calculation, not the entire system, but only a part, namely the guest molecules and part of the framework around the active site, are accounted for during the NMA. As the number of active sites per unit cell may vary depending on the performed simulation, the number of framework atoms included in the NMA will vary. Therefore, more information on the accounted atoms and performed PHVA is presented in Section 1.3 of the Supporting Information. If unwanted imaginary frequencies could not be removed due to a relatively flat potential energy surface, they are substituted with an arbitrary value of $50 \mathrm{~cm}^{-1}$ as is frequently done in literature; however, such substitutions were limited to an absolute minimum. ${ }^{98,99}$

To construct the theoretical IR spectra of pyridine adsorbed on the different active sites, the optimized configurations of adsorbed pyridine are obtained with the same VASP parameters as used for the structural analysis of the active site (vide supra). Afterward, 
Table 1. Textural and Acidic Properties of the Alkaline Earth Metal Modified ZSM-5 Zeolites and of the EFAl Species ${ }^{a}$

\begin{tabular}{|c|c|c|c|c|c|c|c|c|}
\hline Catalyst & $\%$ cation & $V_{\text {pore }}\left(\mathrm{cm}^{3} / \mathrm{g}\right)$ & $V_{\text {micro }}\left(\mathrm{cm}^{3} / \mathrm{g}\right)$ & $S_{\mathrm{BET}}\left(\mathrm{m}^{2} / \mathrm{g}\right)$ & $S_{\text {meso }}\left(\mathrm{m}^{2} / \mathrm{g}\right)$ & $S_{\text {micro }}\left(\mathrm{m}^{2} / \mathrm{g}\right)$ & $C_{\mathrm{BAS}}(\mu \mathrm{mol} / \mathrm{g})$ & $C_{\mathrm{LAS}}(\mu \mathrm{mol} / \mathrm{g})$ \\
\hline Mg-ZSM-5 & 1.4 & 0.22 & 0.14 & 417 & 95 & 322 & 76 & 217 \\
\hline Ca-ZSM-5 & 2.4 & 0.24 & 0.13 & 392 & 77 & 315 & 40 & 228 \\
\hline Sr-ZSM-5 & 5.2 & 0.20 & 0.13 & 379 & 106 & 273 & 85 & 108 \\
\hline Ba-ZSM-5 & 8.2 & 0.18 & 0.12 & 316 & 60 & 256 & 19 & 133 \\
\hline parent ZSM-5_80 & $\mathrm{Si} / \mathrm{Al}=40$ & 0.26 & 0.15 & 448 & 85 & 363 & 232 & 35 \\
\hline DeAl-ZSM-5 & - & 0.26 & - & 384 & 188 & 196 & 37 & 139 \\
\hline Parent ZSM-5_26 & $\mathrm{Si} / \mathrm{Al}=13$ & 0.26 & - & 403 & 148 & 255 & 631 & 168 \\
\hline
\end{tabular}

${ }^{a}$ Note that alkaline-earth metal modified ZSM-5 zeolites have been prepared from the parent ZSM-5_80 zeolite, while the dealuminated EFAl species is extracted from the parent ZSM-5_26 zeolite.

density-functional perturbation theory (DFPT) or linear response theory (LRT) calculations are performed to be able to calculate the vibrational intensities from the Born effective charges (BEC). ${ }^{100-104}$ Finally, the theoretical IR spectra are obtained by fitting Gaussian resolution functions with a width of $7.5 \mathrm{~cm}^{-1}$. No rescaling of the obtained wavenumber was performed as IR scaling factors are mostly calculated for nonperiodic simulations and are shown to be close to 1 for PBE (see also Supporting Information Section 3), certainly for larger basis sets. ${ }^{105,106}$ Just as for the NMA, the PHVA scheme is used (vide supra).

For the calculation of the protonation enthalpy, ${ }^{25}$ the considered intermediates $X$ are adsorbed in both protonated and neutral form in H-ZSM-5, Mg-ZSM-5, Ca-ZSM-5, Sr-ZSM-5, Ba-ZSM-5, and dealuminated ZSM-5. Thereafter, the protonation enthalpy is calculated as

$$
H_{\text {prot }}=H\left(X_{\text {ads }}^{+}\right)-H\left(X_{\text {ads }}\right)
$$

The resulting protonation enthalpies, are depicted in Figure S31 and reported in Table S23 in the Supporting Information).

The theoretical NMR parameters in this work are also calculated with VASP. For the simulation of the chemical shielding tensors, the gauge including projector augmented wave (GIPAW) method is used, ${ }^{107}$ Again the same VASP settings are used as for the other simulations, except for the SCF convergence criterion, which is set at $10^{-8} \mathrm{eV}$, required for an accurate estimation of the theoretical NMR parameters. The computed chemical shielding has been converted to the experimentally observed chemical shift by taking into account a linear relation between both parameters (see Supporting Information Section 1.4).

Molecular dynamics simulations have been applied to better incorporate the effects of mobility and entropy due to finite temperature in which experiments have been performed. We used the CP2K software package ${ }^{108,109}$ and applied the PBE+D3 methodology. The time step is fixed at $0.5 \mathrm{fs}$, while an equilibration period of 5 ps is systematically respected, followed by a production run of at least 25 ps dependent on the type of application.

Two kinds of MD runs have been performed. In the first place, the dynamic behavior of the adsorbate(s) at operating conditions is studied through $\mathrm{MD}$ simulations at a temperature of $500{ }^{\circ} \mathrm{C}$ and a pressure of $1 \mathrm{~atm}$. Second, MD simulations at $27^{\circ} \mathrm{C}$ and $1 \mathrm{~atm}$ have been applied on ZSM-5 structures containing extra-framework complexes to generate different geometrical configurations from which average theoretical NMR parameters are determined at experimental conditions. Further details are given in Section 1.4 of the SI.

2.2. Experimental Details. 2.2.1. Catalyst Synthesis and Characterization. The parent material for the preparation of the alkaline-earth metal modified ZSM-5 samples is based on ZSM-5_80 from Zeolist, with a $\mathrm{Si} / \mathrm{Al}$ ratio of 40 (CBV8014) and a total pore volume of $0.26 \mathrm{~mL} \mathrm{~g}^{-1}$ (see Table 1). Prior to impregnation, the parent material was dried overnight at $120^{\circ} \mathrm{C}$. For each alkaline-earth metal modification, $3 \mathrm{~g}$ of parent ZSM-5 was impregnated with 0.8 $\mathrm{mL}$ of $2.4 \mathrm{M}$ aqueous solution of $\mathrm{Mg}\left(\mathrm{NO}_{3}\right)_{2} \cdot 6 \mathrm{H}_{2} \mathrm{O}, \mathrm{Ca}\left(\mathrm{NO}_{3}\right)_{2} \cdot 4 \mathrm{H}_{2} \mathrm{O}$, and $\mathrm{Sr}\left(\mathrm{NO}_{3}\right)_{2}$. The Ba-modified sample was prepared by triple impregnation with a $0.8 \mathrm{M}$ aqueous solution of $\mathrm{Ba}\left(\mathrm{NO}_{3}\right)_{2}$ with a drying step at $120{ }^{\circ} \mathrm{C}$ for $16 \mathrm{~h}$ after each impregnation. The impregnated powder was placed in a desiccator overnight to achieve complete wetting of the micropores with the precursor solution. Next, the modified zeolite was calcined for $5 \mathrm{~h}$ at $550{ }^{\circ} \mathrm{C}$ with a heating rate of $3{ }^{\circ} \mathrm{C} \mathrm{min}^{-1}$. In this way, modified samples with an alkaline-earth metal to aluminum ratio of 2 are obtained.

Structural and textural properties of the various materials used in this work resulting from the experimental characterization techniques are summarized in Table 1. They show some specific features which make them unique with respect to each other. Despite having the same parent ZSM-5, the choice of the metal in the alkaline-earth metal modified materials has a large impact on the properties. The catalyst modified with complexes of $\mathrm{Ba}$, being the largest of the alkaline-earth metals considered in this work, obviously exhibits the smallest pore volume and surface area $S_{\mathrm{BET}}$ but also causes a 10 -fold decrease in BAS concentration with respect to the parent zeolite. At the same time the concentration of LAS is sufficiently large to generate the smallest ratio $\mathrm{C}_{\mathrm{BAS}} / \mathrm{C}_{\mathrm{LAS}}$ of all materials. Its apparently different behavior with respect to the other metal variants makes the Ba-variant extremely interesting to see its impact in the methylation reactions.

For the preparation of the EFAl species we preferred to take ZSM5 26 as parent material since the effect of dealumination is expected to be more drastic if we start with a zeolite exhibiting a higher acidity (i.e., more BASs) $(\mathrm{Si} / \mathrm{Al}=13) .2 \mathrm{~g}$ of ZSM-5 26 zeolite was loaded onto an alumina crucible and placed in the isothermal zone of a tubular furnace. The furnace was heated at $5{ }^{\circ} \mathrm{C} / \mathrm{min}$ to $700{ }^{\circ} \mathrm{C}$ and kept at $700{ }^{\circ} \mathrm{C}$ for $6 \mathrm{~h}$ under $200 \mathrm{~mL} / \mathrm{min}$ flow of $\mathrm{H}_{2} \mathrm{O}+\mathrm{N}_{2}$ mixture $\left(20 \% \mathrm{H}_{2} \mathrm{O}, 80 \% \mathrm{~N}_{2}\right)$.

The dealuminated sample prepared from parent ZSM-5 26 with a high number of BASs sees a dramatic fall of these Brønsted sites but maintains its pore volume and surface area.

The impact of the acidic properties on the lifetime of the catalyst and on the MTO reaction under reaction conditions will be discussed in the dedicated sections.

2.2.2. Structural and Acidity Characterization. XRD spectra and $\mathrm{N}_{2}$ adsorption isotherms have been measured for all samples and taken up in Section 10 of the SI. The XRD spectra confirm that the single-phase crystalline MFI structure is maintained after modification with alkaline-earth metals and dealumination. The adsorption isotherms deliver some textural properties of the various modified ZSM-5 materials compared with the pristine H-ZSM-5 zeolite (Table 1).

Acidity characterization has been accomplished with transmission FT-IR spectroscopy using pyridine as a probe molecule and using a Nicolet 6700 spectrometer equipped with an MCT/B detector. For the wafer preparation, $50 \mathrm{mg}$ of catalyst were used without any dilution. The specimen was activated in vacuum at $400{ }^{\circ} \mathrm{C}$ for $16 \mathrm{~h}$ to remove adsorbed species. After activation, wafers were saturated with pyridine vapor and further evacuated at $160{ }^{\circ} \mathrm{C}$ for $2 \mathrm{~h}$. Spectra were obtained in the $1000-4000 \mathrm{~cm}^{-1}$ range at $4 \mathrm{~cm}^{-1}$ resolution and after coaddition of 128 scans. The amount of Brønsted and Lewis acid sites was derived from the bands at 1545 and $1456 \mathrm{~cm}^{-1}$ as described elsewhere using extinction coefficients of 1.67 and 2.22, respectively. ${ }^{110}$ Assuming that one molecule of pyridine is adsorbed on one 
a)

(1) Mononuclear

(2) Bi- and mononuclear

(1) Trinuclear

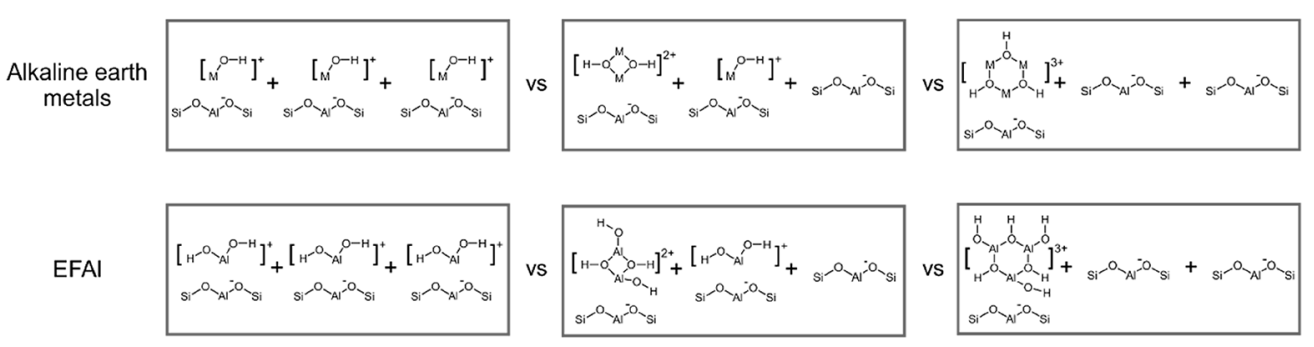

b)
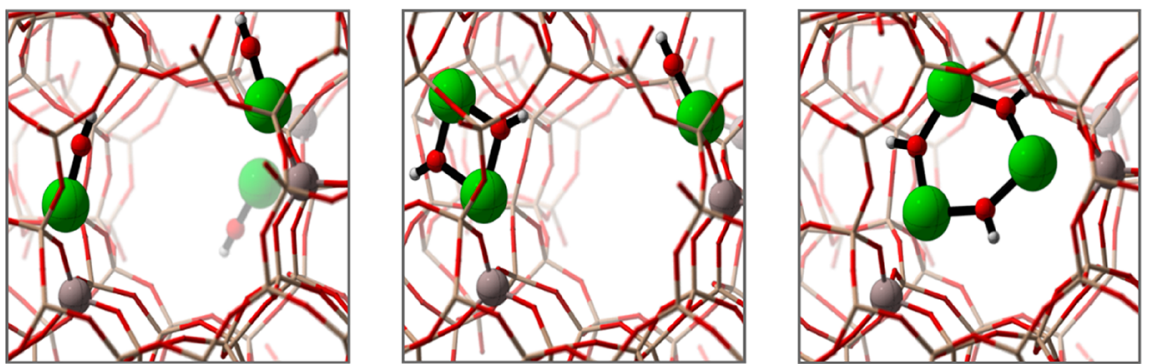

Figure 2. Schematic representation of the structures considered for the relative stability of mono- (left), bi- (center), and trinuclear (right) structures (a) and snapshots of the three considered structures for the Ca case (b).

acid site, the following expressions were used to calculate $C_{B A S}$ and $C_{L A S}$ :

$$
\begin{aligned}
& C_{\mathrm{BAS}}=1.88 \cdot \operatorname{IA}(B) \cdot R^{2} / W \\
& C_{\mathrm{LAS}}=1.42 \cdot \mathrm{IA}(L) \cdot R^{2} / W
\end{aligned}
$$

where IA (BAS, LAS) is the integrated absorbance of the BAS or LAS band $\left(\mathrm{cm}^{-1}\right), R$ is the radius of the catalyst disk $(\mathrm{cm})$, and $W$ is the mass of the catalyst sample $(\mathrm{mg})$.

All magic angle spinning (MAS) solid-state NMR was performed on a $900 \mathrm{MHz}$ Bruker AVANCE IV 21.1 T spectrometer equipped with $4 \mathrm{~mm}$ probes (for $\mathrm{Ca}$ ) and $3.2 \mathrm{~mm}$ probes (for $\mathrm{Al}$ and $\mathrm{H}$ ). ${ }^{1} \mathrm{H}$, ${ }^{27} \mathrm{Al}$, and ${ }^{43} \mathrm{Ca}$ shifts were referenced to tetramethylsilane, $\mathrm{Al}\left(\mathrm{NO}_{3}\right)_{3}$, and saturated $\mathrm{CaCl}_{2}$ solution in $\mathrm{D}_{2} \mathrm{O}$, respectively. Typically recycle delays of $1 \mathrm{~s}$ were used in all cases. The standard Bruker quadrupolar Carr-Purcell-Meiboom-Gill (QCPMG) pulse sequence was used without modification in the case of ${ }^{43} \mathrm{Ca}$ NMR. The ${ }^{27} \mathrm{Al}$ 3QMAS spectra were obtained by utilization of a three-pulse, $\mathrm{z}$-filter sequence. The rf strengths of the first two hard pulses and the third soft selective $90 \mathrm{deg}$ pulse were individually optimized, and the optimized pulse lengths were typically $4.2,1.4$ (both at power level $=282 \mathrm{~W}$ ), and 25 $\mathrm{ms}$ (at power level $=0.5 \mathrm{~W}$ ) for the consecutive pulses. Other relevant acquisition parameters were described in figure captions.

2.2.3. Catalytic Testing. Catalytic experiments were carried out in a Microactivity Reference unit (PID Eng\&Tech) at $500{ }^{\circ} \mathrm{C}$ and ambient pressure. The catalyst (pressed, crushed, and sieved to particle sizes $250-420 \mu \mathrm{m}$ ) was placed in a fixed bed with an internal diameter of $9 \mathrm{~mm}$ for standard experiments. An ISCO pump was used to feed methanol to the reactor system. A w8 hly space velocity (WHSV) of $8 \mathrm{~g}_{\mathrm{MeOH}} \mathrm{g}_{\mathrm{cat}}{ }^{-1} \mathrm{~h}^{-1}$, a $\mathrm{N}_{2} / \mathrm{MeOH}=1: 1$ molar feed composition, and atmospheric pressure were utilized. Conversion, selectivities, and yields were calculated on a molar carbon basis. Thus, conversion was defined as the carbon-based fraction of light oxygenates (methanol and dimethyl ether) consumed during the reaction:

$$
X=\frac{n_{\mathrm{C}, \mathrm{MeOH}_{\text {in }}}-n_{\mathrm{C}, \mathrm{MeOH}_{\text {out }}}-2 \cdot n_{\mathrm{C}, \mathrm{DME}}{ }_{\text {out }}}{n_{\mathrm{C}, \mathrm{MeOH}_{\text {in }}}} \cdot 100 \%
$$

The selectivity toward hydrocarbon products was calculated based on the carbon number. For example, ethene and propene selectivity was calculated as follows:

$$
\begin{gathered}
S_{\text {ethene }}=\frac{2 \cdot n_{\mathrm{C}_{2} \mathrm{H}_{4}}}{n_{\mathrm{C}, \mathrm{MeOH}_{\text {in }}}-n_{\mathrm{C}, \text { oxy }}{ }_{\text {out }}} \cdot 100 \% \\
S_{\text {propene }}=\frac{3 \cdot n_{\mathrm{C}_{3} \mathrm{H}_{6}}}{n_{\mathrm{C}, \mathrm{MeOH}_{\text {in }}}-n_{\mathrm{C}, \text { oxy }}} \cdot 100 \%
\end{gathered}
$$

and the yield of a component $i$ was defined from its selectivity and methanol conversion:

$$
Y_{i}=\frac{S_{i} \cdot X}{100} \%
$$

The performance results are presented in graphs as a function of the methanol mass throughput per amount of catalyst used $\left(\mathrm{g}_{\mathrm{MeOH}}\right.$ $\mathrm{g}_{\mathrm{cat}}{ }^{-1}$ ), and defined as the overall amount $\mathrm{MeOH}$ fed through the catalytic bed before the conversion of oxygenates drops below $80 \%$. Presented selectivities are integral values.

\section{RESULTS AND DISCUSSION}

3.1. Structural Analysis of the Active Site. Depending on the nature of the metal incorporation, the extra-framework species might be present in the zeolite pores as metal cations or charged metal oxide clusters. ${ }^{2,111}$ In earlier work of some of us, these extra-framework LASs were systematically assumed to be composed of binuclear species bridged by $\mathrm{O}$ and $\mathrm{OH}$ ligands. In this sense both $[\mathrm{Ca}(\mu-\mathrm{O})(\mu-\mathrm{OH}) \mathrm{Ca}]^{+}$and $[\mathrm{Ca}(\mu-$ $\left.\mathrm{OH})_{2} \mathrm{Ca}\right]^{2+}$ moieties were proposed as possible modified active sites in Ca-ZSM-5. ${ }^{24,25}$ This suggestion was based on findings in literature that, next to alkaline-earth metals, many other metals such as $\mathrm{Fe}, \mathrm{Ga}, \mathrm{Zn}, \mathrm{Cu}$, and $\mathrm{Al}$ have the tendency to self-organize into multinuclear clusters within the confined space of a zeolite. ${ }^{65,111-116}$

In this work we aim to achieve a deeper understanding of the structure of active sites after incorporation of alkaline-earth metals $\mathrm{Mg}, \mathrm{Ca}, \mathrm{Sr}$, or Ba in ZSM-5 in a combined theoreticalexperimental effort. Theoretically, DFT calculations were carried out to compare the stability of different types of multinuclear complexes. A similar methodology was followed by Liu et al. $^{65}$ in exploring the different nature of extraframework aluminum in faujasite zeolite. In the present work 
the occurrence of mono-, bi-, and trinuclear alkaline-earth metal complexes and EFAls was also explored experimentally by means of a structural analysis on the samples with $\mathrm{Ca}$ modified ZSM-5 materials with ${ }^{43} \mathrm{Ca}$ solid-state solid state NMR. To facilitate the interpretation of the NMR spectra also theoretical calculations were performed to predict the chemical shifts and quadrupole coupling constants of various metal containing species.

3.1.1. Theoretical Study of the Relative Stability of Mono-, $B i-$, and Trinuclear Structures. Extra-framework metal clusters within the zeolite could be represented by multinuclear species such as monomeric, dimeric, or trinuclear species with bridging $\mathrm{O}$ or $\mathrm{OH}$ ligands. It is realistic to assume that apart from binuclear complexes also monomeric and trinuclear species may be formed in the channels of ZSM-5. In each case, the introduction of metal containing species leads to the deprotonation of neighboring BASs, decreasing the BAS density of the material. For binuclear species, it is explicitly shown in Section 2 of the SI that doubly protonated species, i.e. $\left[\mathrm{M}(\mu-\mathrm{OH})_{2} \mathrm{M}\right]^{2+}$, are more stable than lower protonated species.

As a first criterion for the possible occurrence of various multinuclear species, the relative stability of monomeric, dimeric, and trimeric LAS species was investigated. To this end, we construct three structures displayed in Figure 2a with respect to full mass balance in order to enable a straightforward energetic comparison.

To keep charge neutrality, we consider three $\mathrm{Al}$ substitutions per unit cell. In principle, their positions are arbitrary, but it is commonly assumed that some positions are more favorable than others as discussed in ref 117. In Section 1.2 of the SI a plausible configuration is suggested and visualized in Figure $\mathrm{S} 1 \mathrm{a}$, and with respect to these three $\mathrm{Al}$ substitutions, optimized structures of mono-, bi-, and trinuclear species are constructed and visualized in Figure $2 b$ in the case of a Ca-modified ZSM-5 material. The free energies and enthalpies resulting from periodic DFT calculations are summarized in Table 2 and indicate that the formation of mononuclear alkaline-earth metal species is energetically disfavored with respect to binuclear complexes, except for one of the EFAl species which is discussed further. The self-organization of isolated mononuclear cations into binuclear $\left[\mathrm{M}(\mu-\mathrm{OH})_{2} \mathrm{M}\right]^{2+}$ is a highly exothermic process. Multinuclear structures are even more stabilized as far as they can be fitted into the pores of the ZSM-5 zeolite. This result follows the general trend that larger clusters better stabilize the system, as they are submitted to a higher number of coordination interactions with the zeolite framework. However, due to confinement the size of the

Table 2. Free Energies $(\Delta G)$ and Enthalpies $(\Delta H)$ Relative to the Mononuclear Case for All Structures Indicated in Figure 2 (in $\mathrm{kJ} / \mathrm{mol}$ ) and Calculated at $500{ }^{\circ} \mathrm{C}$

\begin{tabular}{|c|c|c|c|c|c|c|}
\hline & \multicolumn{2}{|c|}{$\begin{array}{c}(1) \\
\text { mononuclear }\end{array}$} & \multicolumn{2}{|c|}{$\begin{array}{l}(2) \text { bi- and } \\
\text { mononuclear }\end{array}$} & \multicolumn{2}{|c|}{ (3) Trinuclear } \\
\hline & $\Delta H$ & $\Delta G$ & $\Delta H$ & $\Delta G$ & $\Delta H$ & $\Delta G$ \\
\hline EFAl/I & 0 & 0 & +55 & +114 & +5 & +101 \\
\hline EFAl/II & 0 & 0 & -94 & -79 & +20 & +66 \\
\hline Mg & 0 & 0 & -102 & -48 & -186 & -104 \\
\hline $\mathrm{Ca}$ & 0 & 0 & -153 & -120 & -237 & -194 \\
\hline $\mathrm{Sr}$ & 0 & 0 & -111 & -71 & -198 & -158 \\
\hline $\mathrm{Ba}$ & 0 & 0 & -94 & -73 & -156 & -112 \\
\hline
\end{tabular}

cluster is obviously limited and we therefore discard the possibility that larger clusters than trinuclear alkaline-earth metal complexes will be formed in the ZSM-5 channels, which may play an essential role in the methanol conversion.

The same procedure was applied for the EFAl complexes. However, our study shows that the position of the aluminum substitutions in the framework may have a large effect on the stability of some EFAl species. For the binuclear EFAl species, two configurations were considered, $\mathrm{EFAl} / \mathrm{I}$ with respect to the same $\mathrm{Al}$ substitutions as used for the alkaline-earth metals, whereas $\mathrm{EFAl} / \mathrm{II}$ is based on a different position of the third $\mathrm{Al}$ substitution as visualized in Figure S1b. In the case of EFAl/I, the binuclear complex is less stabilized relative to the monomer (see Table 2), whereas EFAl/II yields binuclear species which are more stable than the monomeric ones, as was found for the alkaline-earth metals. In the remainder of the paper, we will consider both EFAl species to illustrate their noticeable differences in acidic and catalytic properties.

At this point it is interesting to compare our findings with the work of Liu et al. ${ }^{65}$ These authors studied the structure and stability of a wide range of mono-, bi-, tri-, and tetranuclear EFAl complexes at different locations in faujasite. They found similar results as ours and also the reaction energies in the selforganization process are of the same order. The formation of a tri- or tetranuclear cluster was found to be strongly dependent on their location in the zeolite. The preferred position of these multinuclear (cationic) EFAls was found to be localized in the smaller inaccessible sodalite cages of faujasite due to the multiple interactions with the framework. Such locations are expected to interact less with active reacting species due to restricted space available. This is also an indication that not the largest multinuclear moieties but the smaller mono- and binuclear cations will probably have the largest impact on the methylation reaction.

The structures displayed in Figure 2 with three monomers in a unit cell were only used for the computation of stabilization energies. In the following we only regard a single extraframework complex in a unit cell. In the case of a monomer, its structure was optimized with respect to the first $\mathrm{Al}$ substitution Al1. Dimeric species are positioned with respect to All and Al2 (Figure S1). Optimized structures of mono-, bi-, and trinuclear species are visualized in Figure 3 in the case of a Ca-modified ZSM-5 material.

3.1.2. Solid-State NMR on Ca-Modified ZSM-5 Zeolites. To further structurally characterize the nature of the metal containing clusters, a solid state NMR characterization has been performed on Ca-modified ZSM- 5 zeolites from both an experimental and theoretical point of view. For the NMR simulations, the mono-, bi-, and trinuclear extra-framework $\mathrm{Ca}$ species, as discussed in the previous section, are considered. Note that in this case only one mono-, bi-, or trinuclear species have been considered per unit cell, which is charge compensated by one, two, or three aluminum atoms. Periodic DFT calculations of NMR parameters in large zeolite systems, such as ZSM-5, have become feasible lately, as is demonstrated by the works of Dib et al. ${ }^{118}$ and Holzinger et al. ${ }^{119}$ In the first instance, the NMR parameters of the geometrically optimized structures, visualized in Figure 3, will be discussed. The resulting NMR chemical shifts of the ${ }^{43} \mathrm{Ca}$ isotope are listed in Table 3.

The $\mathrm{Ca}$ atom in the mononuclear structure has the lowest chemical shift, which indicates that it is shielded most efficiently. This may seem initially unexpected, as it has only 
a) mononuclear
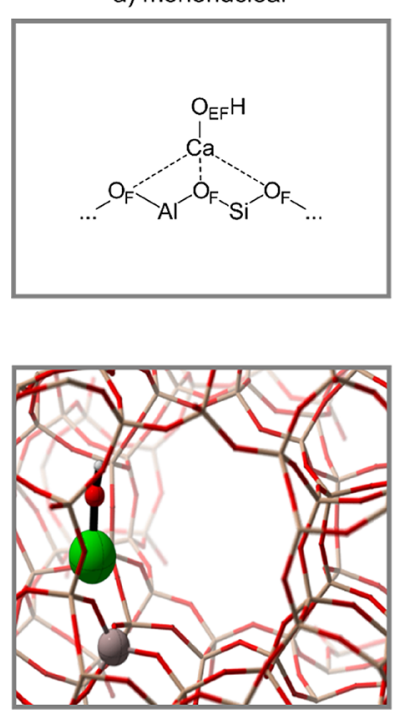

b) binuclear
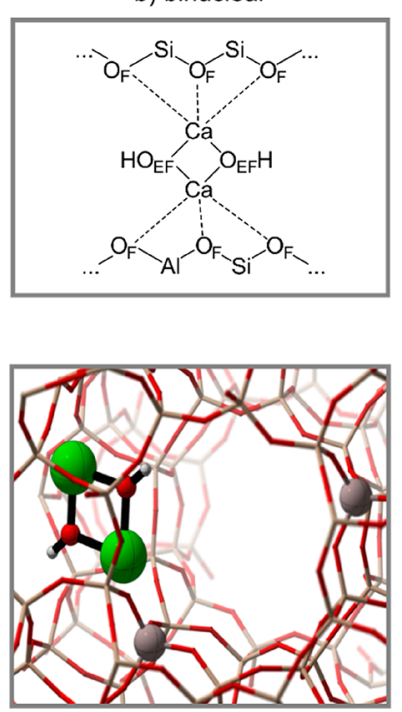

c) trinuclear
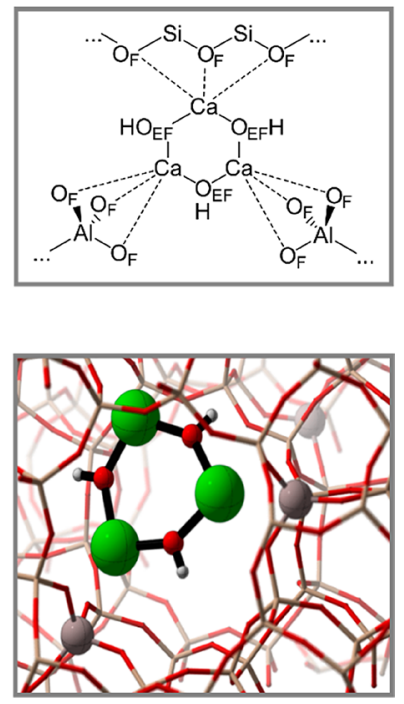

Figure 3. Schematic representation and snapshots of the optimized structures of the isolated extra-framework Ca species in ZSM-5, namely mononuclear (left), binuclear (center), and trinuclear (right).

Table 3. Computed Chemical Shifts of the ${ }^{43}$ Ca Isotope in Extra-Framework Species and Geometry Optimized Distances between the Ca Atom and the O Atoms in ZSM-5 Containing Extra-Framework Species

\begin{tabular}{|c|c|c|c|c|c|c|}
\hline & $\delta_{\text {iso }}(\mathrm{ppm})$ & $\mathrm{CaO}_{\mathrm{EF}, 1}(\AA)$ & $\mathrm{CaO}_{\mathrm{EF}, 2}(\AA)$ & $\mathrm{CaO}_{\mathrm{F}, 1}(\AA)$ & $\mathrm{CaO}_{\mathrm{F}, 2}(\AA)$ & $\mathrm{CaO}_{\mathrm{F}, 3}(\AA)$ \\
\hline \multicolumn{7}{|c|}{ after geometry optimization } \\
\hline mononuclear & -0.32 & 1.99 & - & 2.40 & 2.43 & 2.71 \\
\hline \multirow[t]{2}{*}{ binuclear } & 5.06 & 2.17 & 2.18 & 2.52 & 2.59 & 2.86 \\
\hline & 21.05 & 2.23 & 2.24 & 2.42 & 2.43 & 2.76 \\
\hline \multirow[t]{3}{*}{ trinuclear } & 37.34 & 2.23 & 2.24 & 2.39 & 2.49 & 3.27 \\
\hline & 26.86 & 2.19 & 2.21 & 2.45 & 2.59 & 2.88 \\
\hline & 23.63 & 2.26 & 2.27 & 2.47 & 2.50 & 2.64 \\
\hline \multicolumn{7}{|l|}{ MD snapshots $(300 \mathrm{~K})$} \\
\hline mononuclear (average) & -22.86 & & & & & \\
\hline mononuclear $(\mathrm{min})$ & -32.23 & & & & & \\
\hline mononuclear $(\max )$ & -6.79 & & & & & \\
\hline binuclear (average) & 6.73 & & & & & \\
\hline binuclear $(\min )$ & -11.45 & & & & & \\
\hline binuclear (max) & 23.85 & & & & & \\
\hline trinuclear (average) & 13.63 & & & & & \\
\hline trinuclear $(\mathrm{min})$ & -21.55 & & & & & \\
\hline trinuclear $(\max )$ & 36.22 & & & & & \\
\hline
\end{tabular}

one covalent bond, in contrast to multinuclear species. However, a clear correlation between the chemical shifts and the distances between $\mathrm{Ca}$ and the neighboring oxygens may be established. Hereby a distinction is made between framework oxygens and extra-framework oxygens, labeled as $\mathrm{O}_{\mathrm{F}}$ and $\mathrm{O}_{\mathrm{EF}}$, respectively as schematically shown in Figure 3. The distances for each of the structures are given in Table 3. The distances from the Ca-atom of the monomer to the framework and extraframework oxygens are shorter than in the case of binuclear or trinuclear species. Furthermore, clearly an asymmetry in the $\mathrm{CaO}_{\mathrm{EF}}$ bond distances is observed for the binuclear structure, which gives a lower chemical shift for one of the two $\mathrm{Ca}$ atoms. The trinuclear structure has clearly the highest chemical shift indicating the lowest shielding, which is related to the longer average distance from each $\mathrm{Ca}$ atom to the nearest framework oxygens.

Previous analysis shows that the chemical shift is very sensitive to the geometrical configuration and in particular the
$\mathrm{CaO}$ distances. In this sense, we opted to also calculate NMR properties at finite temperature taking snapshots from $\mathrm{MD}$ simulations (see Supporting Information Section 1 for more details), as the NMR experiments were performed at $300 \mathrm{~K}$ (vide infra). The results are presented in Table 3.

At $0 \mathrm{~K}$, the monomer exhibits a chemical shift of $-0.32 \mathrm{ppm}$, but taking into account the framework flexibility and mobility of this structure at finite temperature it is observed that the chemical shift becomes more negative with an average of -23 ppm. In the static case, the monomer is only 4-fold coordinated (left panel in Figure 3); however, at finite temperatures the Ca-atom centers itself between multiple framework oxygens, hence increasing the chemical shielding. Note that this structure resembles the $\mathrm{ZO}-\mathrm{Ca}-\mathrm{OH}$ site, as suggested by Zhang et al. ${ }^{27}$ More information can be found in the SI (Section 2.2.1 and Figure S14). For the binuclear complex, two Ca-atoms contribute to the NMR spectrum, which yields an average chemical shift of 6.73 ppm. However, 
the ${ }^{43} \mathrm{Ca}$ chemical shifts can cover a broad range of $35 \mathrm{ppm}$ (-11-24 ppm).

The trinuclear moiety is less mobile, the third substituted $\mathrm{Al}$ atom lies at the next intersection of the straight and zigzag channel (see Al3 in Figure S 1 of the SI), and its configuration is more or less anchored in the channels. Its structure during the MD simulation at $300 \mathrm{~K}$ does not vary too much from its 0 $\mathrm{K}$ structure, yielding an average chemical shift around $13 \mathrm{ppm}$ compared to the static value of $30 \mathrm{ppm}$ (Table 3). They are expected to mainly contribute to the positive range of the NMR spectrum.

In order to complement the theoretical investigation, several high-field solid-state NMR spectroscopic experiments on ${ }^{43} \mathrm{Ca}$ enriched ZSM5 have been performed. ${ }^{43} \mathrm{Ca}$ solid state NMR is intrinsically challenging because ${ }^{43} \mathrm{Ca}$ is a quadrupolar nucleus ( spin $=7 / 2)$ with relatively low gyromagnetic ratios as well as with a very low natural abundance (only $0.135 \%$ ). Until now, the scientific community only measured simple Ca-salts (e.g., $\mathrm{CaCO}_{3}$ or hydroxyapatites), which are characteristically homogeneous in nature. ${ }^{120-122}$ However, no real efforts have been made to investigate more complex and heterogeneous materials (particularly entrapped/embedded/grafted into a porous material), and thus, our attempt constitute a challenge by itself.

The solid-state Hahn Echo NMR spectrum (Figure 4) of ${ }^{43}$ Ca-enriched ZSM5 displays a relatively broader response (than usual Ca-salts), the peak with the highest intensity centered around $0.6 \mathrm{ppm}$, which inevitably advocates for the heterogeneity within the sample. Next, to derive more structural information about the residual Ca-species and enhance the sensitivity, quadrupolar Carr-Purcell-Meiboom-Gill (QCPMG) measurement has been performed (Figure 4). Interestingly, the observed nonsymmetric nature of the QCPMG spectrum reveals the existence of more than one nonidentical Ca-species. If we compare the experimental peak positions with our simulated chemical shift values at $300 \mathrm{~K}$ ( $\delta_{\text {iso }}$ values in MD snapshots) as well as after the geometry optimizations, it is safe to conclude that binuclear species definitely exist in the Ca-ZSM5 sample. As no substantial contribution in the positive range of the $\mathrm{Ca}$ chemical shift spectrum is observed, it is reasonable to assume that trinuclear species will only be present to a minor extent. In addition, ${ }^{1} \mathrm{H}-{ }^{1} \mathrm{H}$ two-dimensional double-quantum (DQ) NMR experiments clearly reveal the existence of a new peak around 3.50 ppm (indicated in red in Figure 5) in addition to the usual 1.4-1.6 ppm peak due to the BAS of zeolite (Figure 5), which could be attributed to the hydroxy group attached to the multinuclear Ca-species.

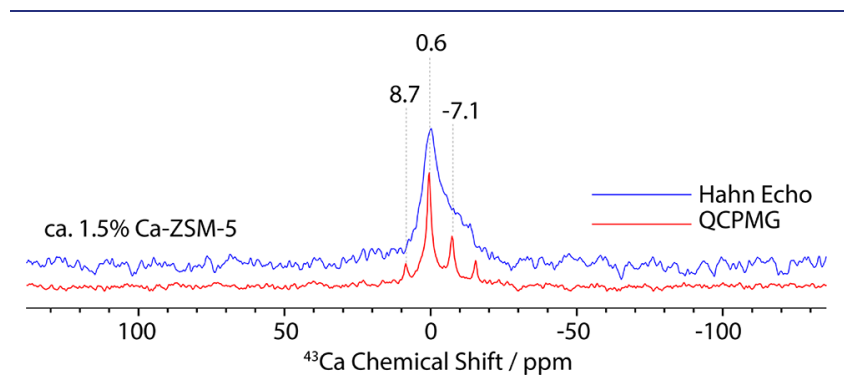

Figure 4. ${ }^{43} \mathrm{Ca}$ magic angle spinning (MAS) solid-state hahnecho (blue) and QCPMG (red) NMR spectra of ca. 1.5\% Ca-ZSM-5 [900 $\mathrm{MHz}, 10 \mathrm{kHz}$ MAS, recycle delays $=1 \mathrm{~s}$, Number of scans $=14 \mathrm{k}]$.
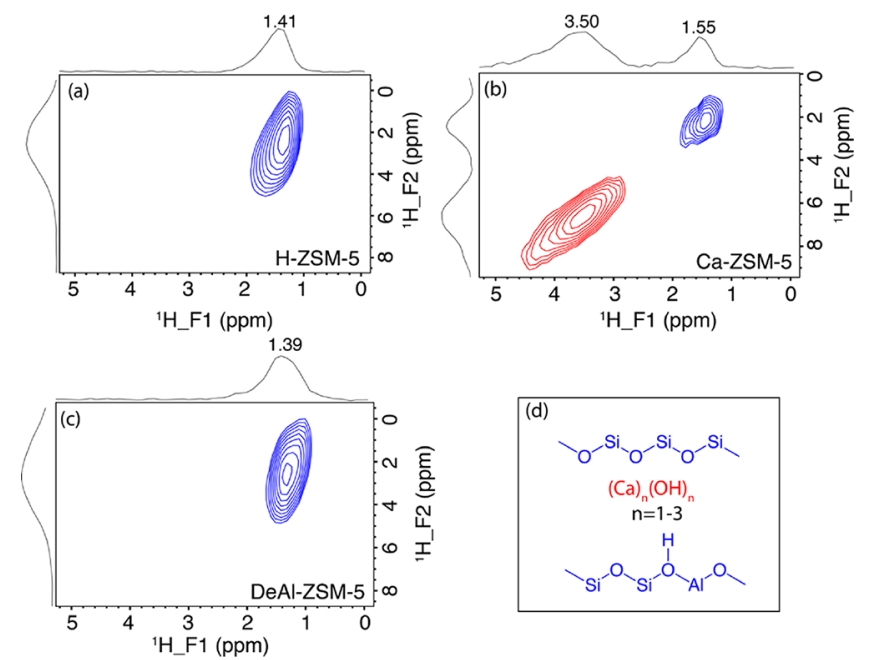

Figure 5. ${ }^{1} \mathrm{H}-{ }^{1} \mathrm{H}$ Two-dimensional DQMAS NMR spectra of zeolite (a) ZSM-5, (b) 6\% Ca-ZSM-5, (c) dealuminated ZSM-5, and (d) simplified pictorial representation of responsible proton containing entities.

Previous analysis gives indirect evidence that both monoand binuclear species may be present in the alkaline-earth metal modified ZSM-5 catalysts. In the remainder of this paper, we have systematically performed the acidity characterization simulations and methylation reactions with both monoand binuclear species. However, as will become clear (vide infra), mononuclear species impact the catalytic activity to a lesser extent, advocating our earlier assumptions on the nature of extra-framework binuclear species in postsynthetically modified samples.

3.2. Acidity Characterization: BAS/LAS Nature of the Active Site. From the previous analysis, it was shown that metal oxide clusters reduce the number of vicinal BASs, yielding new Lewis acid sites associated with the metal oxide clusters. Furthermore also EFAl species have Lewis acid properties. ${ }^{24,25,72-74}$ The nature and strength of acid sites can be characterized experimentally by various techniques. ${ }^{123-127}$ Herein we characterized the acidic properties using IR spectroscopy with pyridine as a probe molecule from both an experimental and theoretical point of view. Pyridine adsorption is able to discriminate between Brønsted and Lewis acid sites as distinct peaks in the region from $1700 \mathrm{~cm}^{-1}$ until $1400 \mathrm{~cm}^{-1}$ appear in the spectra. Pyridine is protonated upon adsorption on a BAS forming a pyridinium ion and only coordinatively bonds toward an LAS. ${ }^{128,129}$ This difference leads to a characteristic peak in the IR spectrum around 1545 and $1450 \mathrm{~cm}^{-1}$ for a BAS and LAS, respectively. ${ }^{24,45,128,130-134}$ Furthermore, the vibrational mode in the region of $1580-1630$ $\mathrm{cm}^{-1}$ is indicative for the global acidic strength as was shown by Velthoen et al. ${ }^{129}$

To characterize the BASs and LASs theoretically, pyridine adsorption is studied on both mono- and binuclear alkalineearth metal modified ZSM-5, on EFAls, and on pristine $\mathrm{H}$ ZSM-5 with a specific number of BASs as reference. The resulting optimized structures together with the adsorption enthalpy are depicted in Figure 6 confirming the distinct adsorption on a BAS and LAS. On a BAS, pyridine is immediately protonated, whereas on the metal complexesboth mono- and binuclear-pyridine makes a coordination with the alkaline earth metal or $\mathrm{Al}$ in the EFAl species, 
a. Mononuclear
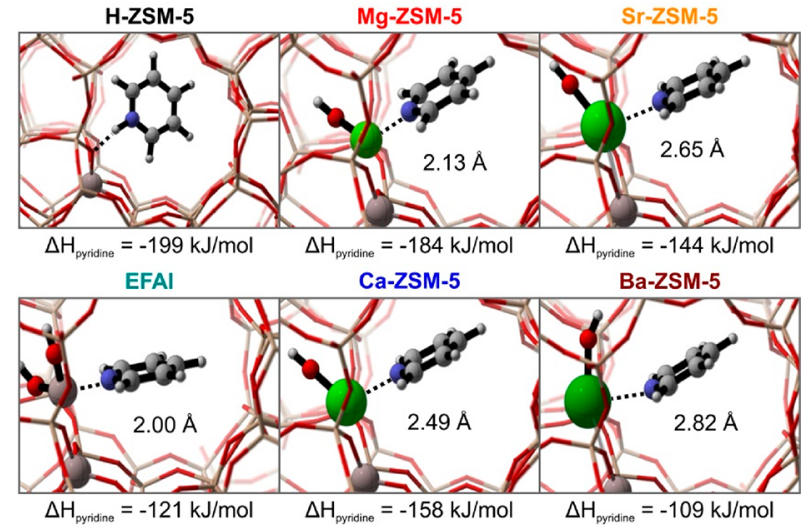

b. Binuclear
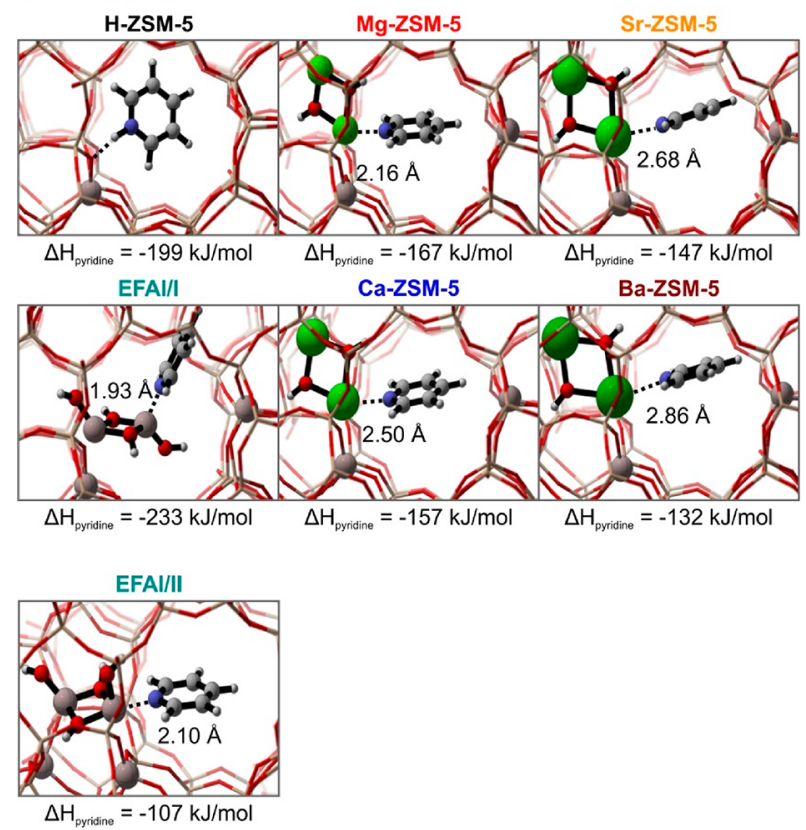

Figure 6. Pyridine adsorption to a mononuclear LAS (a) and a binuclear LAS (b). Also given are the adsorption enthalpies in $\mathrm{kJ} / \mathrm{mol}$ belonging to the optimized structures at $0 \mathrm{~K}$ of pyridine adsorbed in pristine H-ZSM-5, extra-framework aluminum in ZSM-5 and Mg, Ca, $\mathrm{Sr}$ or Ba-ZSM-5. To keep the charge in balance frameworks with only one $\mathrm{Al}$ substitution are considered in case of monomers, and with two $\mathrm{Al}$ substitutions in case of the binuclear species. In the pristine $\mathrm{H}$ ZSM- 5 only one single BAS and thus one $\mathrm{Al}$ substitution is taken into account. For the snapshots, the following color code is used: white is $\mathrm{H}$, light gray is $\mathrm{C}$, blue is $\mathrm{N}$, red is $\mathrm{O}$, gray is $\mathrm{Al}$, beige is $\mathrm{Si}$, and green is the alkaline earth metal.

confirming the presence of Lewis acid sites. Special attention is given to the two embedded $\left[\mathrm{HOAl}(\mu-\mathrm{OH})_{2} \mathrm{AlOH}\right]^{2+}$ structures (EFAl/I and $\mathrm{EFAl} / \mathrm{II})$ to illustrate the impact their position in the channels of the zeolite has on acidic and catalytic properties, as shown by the adsorption distance and adsorption enthalpy in Figure 6.

A further characterization of the LAS and BAS is performed by comparing simulated and experimental IR spectra. The experimental spectra of all samples are collected in Figure 7. They are compared with the theoretical spectra obtained after adsorption of pyridine on binuclear modified ZSM-5 materials. There is a very good agreement between theory and experiment. a.

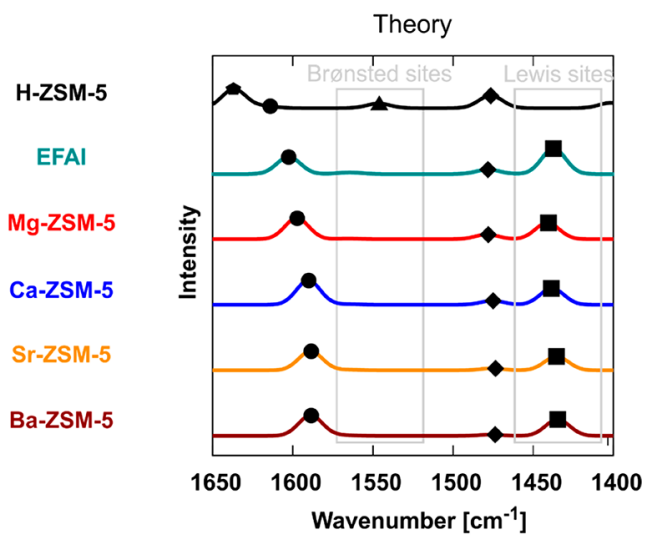

b.

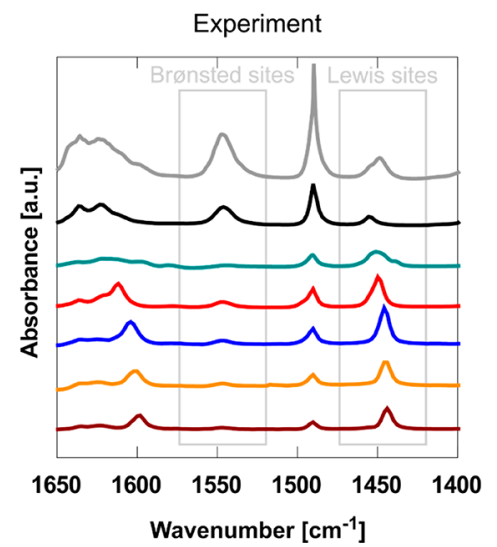

Figure 7. FTIR spectra of various zeolitic materials using pyridine as a probe molecule. (a) Theoretical spectrum of pyridine adsorbed on modified ZSM-5 materials with binuclear species, (b) experimental spectrum.

First, the peak corresponding to the BAS, around $1545 \mathrm{~cm}^{-1}$, can be recognized in both the theoretical $(\Delta)$ and experimental spectrum of pristine H-ZSM-5. On the other hand, this peak is also found in the experimental spectrum for modified ZSM-5, albeit with a lower intensity, and it does not appear in the theoretical spectrum. This difference could be because a fraction of isolated BASs is still present in the actual modified catalyst, while this is not considered in the unit cell in the theoretical calculations where the number of $\mathrm{Al}$ substitutions is restricted to a minimum to impose charge neutrality. Second, the LAS peak, around $1450 \mathrm{~cm}^{-1}$, is encountered in the theoretical $(\square)$ and experimental spectra of dealuminated, Mg-, Ca-, Sr-, and Ba-ZSM-5. This band is also found in the experimental pristine H-ZSM-5 spectrum, but not in the corresponding theoretical spectrum. This peak is experimentally assigned to extra-framework $\mathrm{Al}$ species, ${ }^{24,135}$ which are again not accounted for in the unit cell used during the theoretical simulations of pristine H-ZSM-5, thus explaining the difference. Furthermore, the assignment of this peak to EFAl species is confirmed by the simulations of an isolated EFAl structure, as its IR spectrum shows this Lewis acid site peak.

Finally, a peak not ascribed to either the BAS or the LAS appears in both the theoretical $(\diamond)$ and experimental spectra for all considered structures around $1475 \mathrm{~cm}^{-1}$, which can be related to some specific molecular surface vibrations as described in detail in Section 3 of the Supporting Information.

Our theoretical and experimental spectra confirm that Lewis acid sites are introduced in the modified catalyst, which goes 

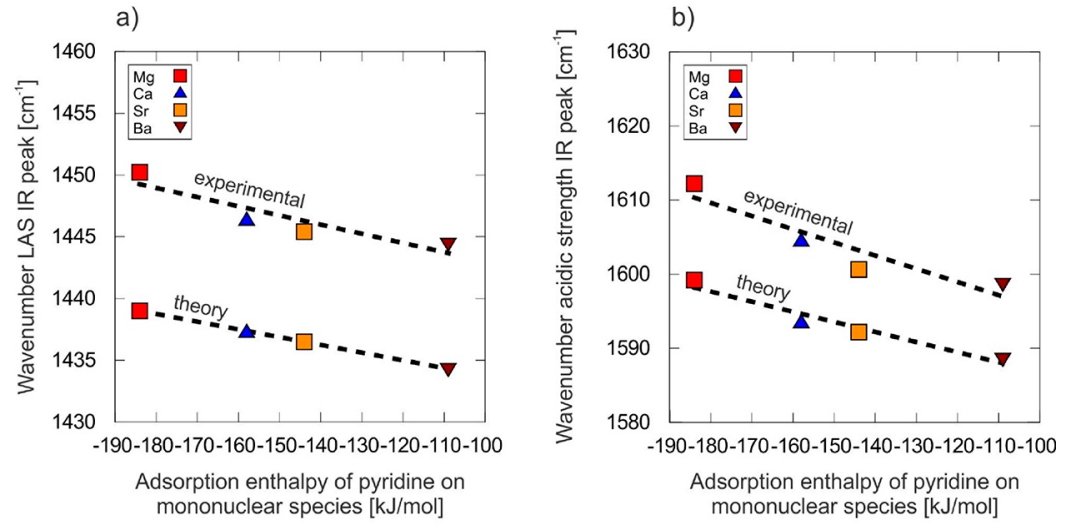

c)
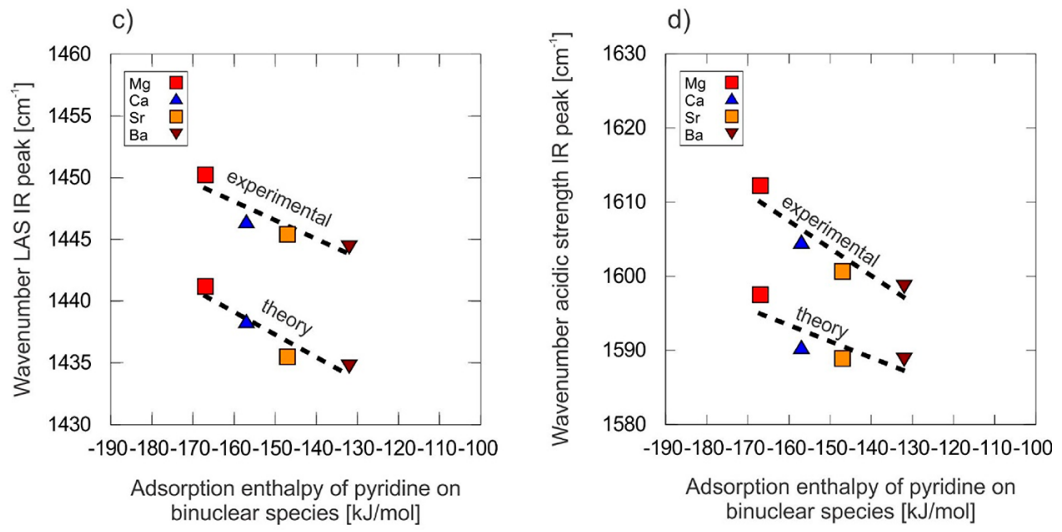

Figure 8. Shifts in the LAS ( $a$ and $c$ ) and global acidity (b and d) peaks in the IR spectrum with respect to changes in the strength of the incorporated mono- ( $a$ and $b$ ) or binuclear ( $c$ and d) LASs.

hand in hand with the elimination of Brønsted acid sites. The correspondence between theoretical and experimental spectra gives strong evidence that the $\left[\mathrm{M}(\mu-\mathrm{OH})_{2} \mathrm{M}\right]^{2+}$ representation of the active site on a molecular level is realistic, although the monomeric $[\mathrm{M}(\mu-\mathrm{OH})]^{+}$alkaline-earth metal complexes yield a similar behavior.

Depending on the nature of the metal incorporated cationic cluster, subtle shifts are found in the peak at $1450 \mathrm{~cm}^{-1}$ assigned to Lewis acidity. Furthermore blue-shifted vibrational modes in the region $\left(1580-1630 \mathrm{~cm}^{-1}\right)$ are also characteristic for the global acidic strength of the complex as shown in the work of Velthoen et al. ${ }^{129}$ It is now interesting to investigate whether a correlation can be found between these blue shifts and the strength of the incorporated LASs in the zeolite framework. To this end we calculated the adsorption enthalpy of pyridine on the mono- and binuclear metal oxide clusters. The results are shown in Figure 6 together with the distance between the nitrogen of pyridine and the metal of the cluster. The absolute values may be compared to some other adsorption enthalpies in zeotype materials. ${ }^{136}$ As can be expected, the results for the alkaline earth metals show that a more negative adsorption enthalpy leads to a shortened nitrogen-metal distance and thus a stronger Lewis acidity $(\mathrm{Mg}$ $>\mathrm{Ca}>\mathrm{Sr}>\mathrm{Ba}$ ). More interestingly, for the alkaline earth metals, the adsorption enthalpies can be correlated to the information on the IR peak that is characteristic for the LAS (around $1450 \mathrm{~cm}^{-1}$ ) and peak characteristic for the global acidic strength $\left(1580-1630 \mathrm{~cm}^{-1}\right)$, as a stronger adsorption enthalpy yields an increased wavenumber and thus blue-shifted peaks. This correlation is close to linear for both peaks as can be seen on the plots depicted in Figure 8. This correlation might serve as a very insightful catalyst design guideline, as it directly yields information on the strength of incorporated LASs in zeolites.

For both mono- and binuclear alkali-earth metals we observe a very good agreement between theory and experiment. Both experimental and theoretical data points clearly show a linear relationship. The slope of the linear regression is even perfectly reproduced. We need only a rescaling of the theoretical estimates for an exact reproduction.

A special note should be made to the binuclear EFAl species, as their acidic properties are very much dependent on the used Al substitutions (EFAl/I vs EFAl/II). More information is given in Section 3.2 of the SI. While the data points of the $\mathrm{EFAl} / \mathrm{I}$ complexes have a tendency to lie on the linear regression, those belonging to $\mathrm{EFAl} / \mathrm{II}$ do not show any relationship with the alkaline-earth metals. A further investigation on the nature of all possible EFAl species is beyond the scope of this work, but our results clearly show that the exact nature of EFAl species should be further investigated in future studies.

3.3. Reactivity Properties of the Active Site. From the previous analysis a decreased Lewis acid strength was observed in the following series $\mathrm{Mg}, \mathrm{Ca}, \mathrm{Sr}$, and $\mathrm{Ba}$. To assess the influence of these intrinsic acidic properties on the catalytic behavior, we studied methylation reactions of propene and benzene and some other methylated aromatic species, which are typically present in the hydrocarbon pool, with methanol. Both reactions are initiating steps in the aromatics and alkene cycle of the MTO process (Figure 1) and are identified as key reaction steps for carbon incorporation. ${ }^{33-41}$ Furthermore the influence of LAS incorporation on the formation of the 
protonated, and thus activated, ${ }^{25,35,137}$ form of some HP intermediates (depicted in Figure 1) is also investigated. In our earlier work we found evidence that incorporation of LASs selectively destabilizes crucial cyclic carbocationic HP compounds. $^{25}$

We first assess the impact of the presence of binuclear $[\mathrm{M}(\mu$ $\left.\mathrm{OH})_{2} \mathrm{M}\right]^{2+}$ moieties in the catalyst on the methylation kinetics. The reactions are studied at three distinct active sites as shown in Figure 9. We distinguish an isolated BAS, a BAS in the vicinity of a LAS, and an isolated LAS, since methylation is also known to occur over Lewis acid sites. ${ }^{138,139}$ Furthermore the experimental IR spectra in Figure 7 suggest that both BAS and LAS are encountered in every considered catalyst. On an isolated LAS, methanol is activated by adsorption on the LAS of the $\left[\mathrm{M}(\mu-\mathrm{OH})_{2} \mathrm{M}\right]^{2+}$ moiety, rather than being adsorbed on the weak bridging Brønsted acidic $\mathrm{OH}$ site of the metal species. But in the case of a combined LAS/BAS catalyst, the reactants can freely adsorb on the two acid sites. Therefore we considered two cases, namely the $\mathrm{BAS} /\left[\mathrm{M}(\mu-\mathrm{OH})_{2} \mathrm{M}\right]^{2+}$ where the methanol is first adsorbed on the BAS and the $\left.\mathrm{M}(\mu-\mathrm{OH})_{2} \mathrm{M}\right]^{2+} / \mathrm{BAS}$ where methanol is first adsorbed on the LAS.

The corresponding free energy diagrams at $500{ }^{\circ} \mathrm{C}$ for all cases are shown in Figure 10, and the detailed free energies along the reaction profile are tabulated in Table S13 and Table S14. The corresponding results for the EFAl species are discussed in Section 7 of the SI. Furthermore, the results of the mononuclear $[\mathrm{CaOH}]^{+}$species are discussed in Section 6 of the SI and further in this section.

The empty zeolite and methanol and the hydrocarbon (propene or benzene) in the gas phase are chosen as the reference state. Methanol adsorbs first on the BAS or isolated LAS, after which the hydrocarbon coadsorbs, which is the standard procedure to construct methylation reaction profiles. ${ }^{140,141}$ Overall our adsorption data on H-ZSM-5 agree well with literature data; only the coadsorption of benzene is slightly underestimated, as indicated by the enthalpy data in Section 5 of the Supporting Information. $140-143$

The adsorption of methanol shows two clear trends. First, adsorption of methanol on a BAS is barely influenced by a nearby $\left[\mathrm{M}(\mu-\mathrm{OH})_{2} \mathrm{M}\right]^{2+}$ moiety, since the reaction profiles practically coincide in the first step of Figure 10a and Figure 10b. Second, the adsorption enthalpies listed in Table S15 and Table S16 of the Supporting Information show that methanol is slightly weaker adsorbed on an isolated alkaline earth metal cluster than on a BAS. This trend is in perfect agreement with the pyridine adsorption data and the Lewis acidity scale proposed in Figure 8 with the following Lewis acidity order $\mathrm{Mg}$ $>\mathrm{Ca}>\mathrm{Sr}>\mathrm{Ba}$. In any case, the adsorption is assumed to be

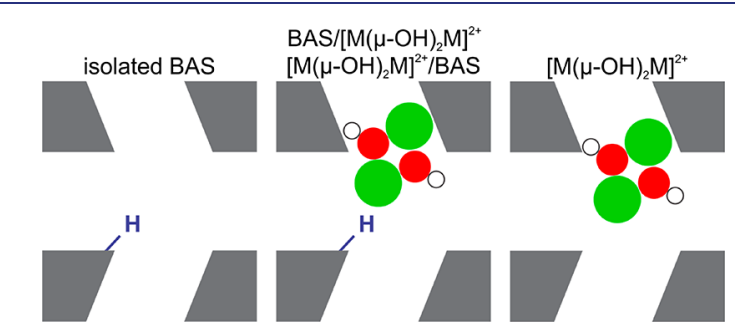

Figure 9. Schematic representation of the three active sites considered for the methylation reactions, namely an isolated BAS, a BAS near a $\left[\mathrm{M}(\mu-\mathrm{OH})_{2} \mathrm{M}\right]^{2+}$ moiety, and an isolated $\left[\mathrm{M}(\mu-\mathrm{OH})_{2} \mathrm{M}\right]^{2+}$ moiety. strong enough in all cases to activate the methanol, to ensure sufficient methanol coverage on the active site and to allow us to model the methylation reaction in the same manner on both active sites. A more detailed discussion on the difference between adsorption on a LAS and BAS can be found in Section 4 of the Supporting Information. ${ }^{83,143,144}$

For the coadsorption of benzene or propene, a higher stability for the coadsorbed methanol and benzene/propene is observed for the BAS $/\left[\mathrm{M}(\mu-\mathrm{OH})_{2} \mathrm{M}\right]^{2+}$ active sites. This effect can be ascribed to the availability of both a BAS and LAS, enabling the possibility for methanol to adsorb on the BAS, whereas the hydrocarbon is coordinatively bound to the LAS via orientation of the $\pi$-electrons toward the metal of the $\left[\mathrm{M}(\mu-\mathrm{OH})_{2} \mathrm{M}\right]^{2+}$ moieties. A snapshot is presented in Figure 11. The cooperative role of the LAS and BAS yields in this case an extra stabilization as the reactants can freely adsorb on the two acid sites. In principle we could interchange the adsorption on the BAS and the LAS. To this end, all adsorption and reaction steps of the methylation profile are recalculated but now with methanol first adsorbing on the LAS and the hydrocarbon on the BAS (notation $\left[\mathrm{M}(\mu-\mathrm{OH})_{2} \mathrm{M}\right]^{2+} / \mathrm{BAS}$ ). The resulting profile is displayed in Figure $10 \mathrm{e}$ and $\mathrm{f}$ and compared with the previous results (BAS/ $\left[\mathrm{M}(\mu-\mathrm{OH})_{2} \mathrm{M}\right]^{2+}$ and isolated $\left.\left[\mathrm{M}(\mu-\mathrm{OH})_{2} \mathrm{M}\right]^{2+}\right)$. The interchange of the order of the active sites has a significant influence on the coadsorption and kinetics of the methylation reaction. The state in which both methanol and benzene are coadsorbed shows a significant destabilization in the $\left[\mathrm{M}(\mu-\mathrm{OH})_{2} \mathrm{M}\right]^{2+} /$ BAS case compared to the $\mathrm{BAS} /\left[\mathrm{M}(\mu-\mathrm{OH})_{2} \mathrm{M}\right]^{2+}$ case. Furthermore, the overall free energy barriers are at least 100 $\mathrm{kJ} / \mathrm{mol}$ higher in $\left[\mathrm{M}(\mu-\mathrm{OH})_{2} \mathrm{M}\right]^{2+} / \mathrm{BAS}$ than in $\mathrm{BAS} /[\mathrm{M}(\mu$ $\left.\mathrm{OH})_{2} \mathrm{M}\right]^{2+}$, implying that methanol will preferentially adsorb on the BAS and the hydrocarbon on the LAS. Those results are in agreement with the stronger adsorption energies of pyridine on a pristine BAS site compared to the various LAS sites (Figure 6). We also observe that the results on the transition state region of $\left[\mathrm{M}(\mu-\mathrm{OH})_{2} \mathrm{M}\right]^{2+} / \mathrm{BAS}$ are quite similar to the isolated LAS moiety.

A double adsorption site is not available for the isolated BAS and isolated $\left[\mathrm{M}(\mu-\mathrm{OH})_{2} \mathrm{M}\right]^{2+}$ systems, where benzene or propene are coadsorbed in the zeolites without any specific interactions with an active site, as indicated in the snapshots shown in Figure 11.

The presence of $\left[\mathrm{M}(\mu-\mathrm{OH})_{2} \mathrm{M}\right]^{2+}$ moieties also significantly affects the intrinsic free energy barriers for methylation of benzene, as can be seen in Table S13 in the Supporting Information. The resulting free energy barriers may be compared with available data in literature and are of the same order of magnitude. ${ }^{25,84,85,140,141,145}$ For LASs there is only limited literature data available from the work of Vos et al. ${ }^{146}$ on electrophilic aromatic substitution, which were obtained at a rather low level of theory.

Our data summarized in Table S12 show that in all cases the intrinsic free energy barrier for methylation reactions taking place on a BAS near an LAS or on an LAS are substantially higher than on a pristine BAS site. When considering the alkaline earth metals, the observed increase is higher for methylations of benzene compared to those of propene. For the methylations, a $\left[\mathrm{M}(\mu-\mathrm{OH})_{2} \mathrm{M}\right]^{2+}$ moiety in the neighborhood of the BAS leads to an increase of the intrinsic free energy barrier of 42 to $107 \mathrm{~kJ} / \mathrm{mol}$ for benzene and an increase of 14 to $40 \mathrm{~kJ} / \mathrm{mol}$ for propene, depending on the considered metal oxide cluster. On the other hand, the methylation over 

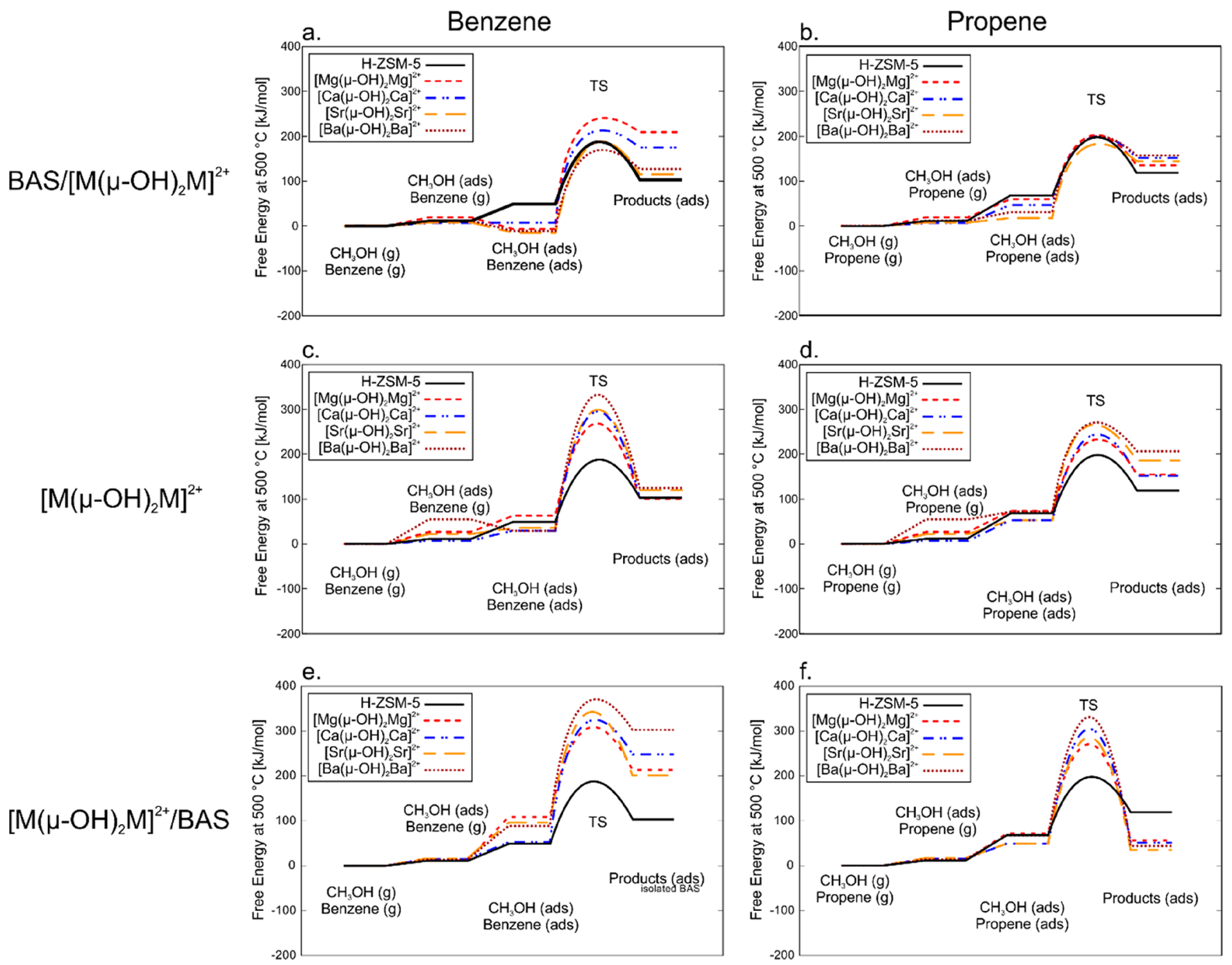

Figure 10. Free energy profiles at $500{ }^{\circ} \mathrm{C}$ for the methylation of benzene and propene over several active sites, namely an isolated BAS (full black line), a BAS near an $\left[\mathrm{M}(\mu-\mathrm{OH})_{2} \mathrm{M}\right]^{2+}$ where the methanol is adsorbed on the BAS (a and b), an isolated $\left[\mathrm{M}(\mu-\mathrm{OH})_{2} \mathrm{M}\right]^{2}(\mathrm{c}$ and d) and a $[\mathrm{M}(\mu$ $\left.\mathrm{OH})_{2} \mathrm{M}\right]^{2+}$ moiety near a BAS, indicated by $\left[\mathrm{M}(\mu-\mathrm{OH})_{2} \mathrm{M}\right]^{2+} / \mathrm{BAS}$, where the methanol is adsorbed on the LAS (e and $\left.\mathrm{f}\right) . \mathrm{M}$ is one of the considered alkaline earth metals $(\mathrm{Mg}, \mathrm{Ca}, \mathrm{Sr}$, or $\mathrm{Ba})$.

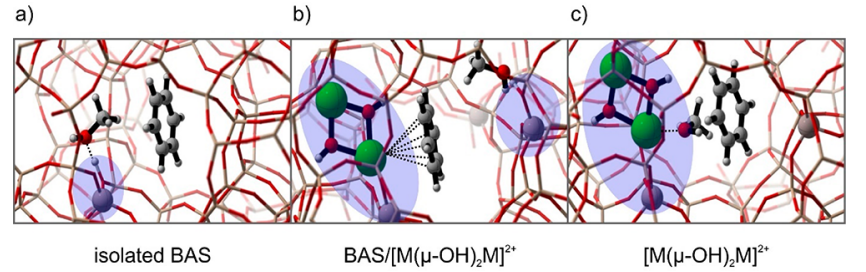

Figure 11. Snapshots of the prereactive complex for the methylation of benzene in Ca-ZSM-5 as representative for the other considered metal substituted clusters $(\mathrm{M}=\mathrm{AlOH}, \mathrm{Mg}, \mathrm{Ca}, \mathrm{Sr}$, and $\mathrm{Ba})$, showing the two available adsorption sites (indicated in blue) in the BAS/ $\left[\mathrm{M}(\mu \mathrm{OH})_{2} \mathrm{M}\right]^{2+}$ case (b) in contrast to the isolated BAS (a) and isolated LAS (c).

an isolated $\left[\mathrm{M}(\mu-\mathrm{OH})_{2} \mathrm{M}\right]^{2+}$ moiety leads to an increase of the intrinsic free energy barrier of 70 to $165 \mathrm{~kJ} / \mathrm{mol}$ and 29 to 85 $\mathrm{kJ} / \mathrm{mol}$ compared to an isolated BAS for benzene and propene, respectively. The behavior of the isolated EFAl species deviates from those of the alkaline-earth metal species. We therefore opt to separate their results from the other metals and to discuss their reaction kinetics in a separate energy profile (Figure S30 in Section 7 of the SI).

The overall increase of the reaction barrier noticed in the alkaline-earth metal complexes can be linked to a deformation of the transition states over a BAS near an LAS or an isolated LAS. In the snapshots depicted in Figure 12 for benzene methylation over an isolated BAS and an isolated $[\mathrm{Ca}(\mu$ $\left.\mathrm{OH})_{2} \mathrm{Ca}\right]^{2+}$, a deviation of the planarity of the transferred
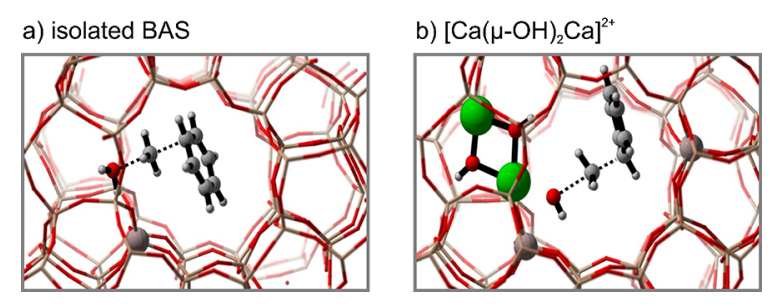

Figure 12. Snapshots of the transition state of the methylation of benzene over an isolated BAS (a) and an isolated $\left[\mathrm{Ca}(\mu-\mathrm{OH})_{2} \mathrm{Ca}\right]^{2+}$ cluster showing the planarity deviation of the methyl group near the LAS. More snapshots can be found in Figure S26 of the SI. 

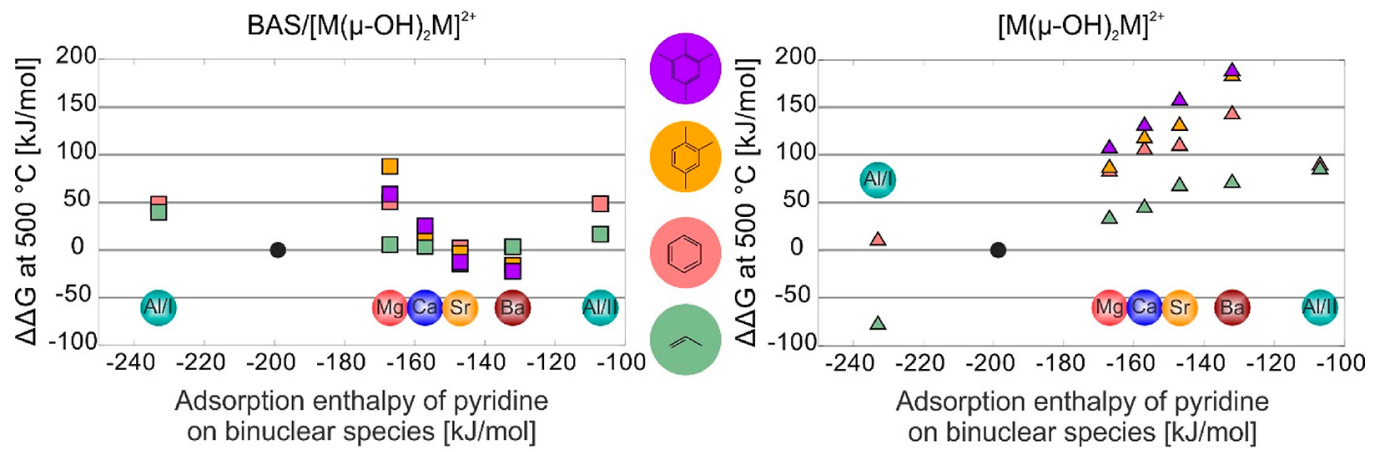

Figure 13. Change in the overall free energy barrier at $500{ }^{\circ} \mathrm{C}$ of the methylation of benzene (red), propene (green), pseudocumene (orange), and durene (purple) over an BAS near a $\left[\mathrm{M}(\mu \text {-OH })_{2} \mathrm{M}\right]^{2+}$ moiety (left and $\square$ ) and an isolated $\left[\mathrm{M}(\mu \text {-OH })_{2} \mathrm{M}\right]^{2+}$ moiety (right and $\left.\Delta\right)$ relative to the methylation rate over an isolated BAS (black circle) is plotted in function of the pyridine adsorption enthalpy. For the dealuminated species both $\mathrm{EFAl} / \mathrm{I}$ and $\mathrm{EFAl} / \mathrm{II}$ variants are considered.

methyl group can be distinguished compared to the transition state over an isolated BAS. Snapshots for other methylation reactions can be found in Figure S26 in the SI. The deformation is quantified by calculating the dihedral angle of the methyl group for the different transition states which is tabulated in Table S11 of the Supporting Information. The values confirm the deviation for all alkaline earth metals and show that it is more significant for benzene than for propene. Furthermore the observed effects can be corroborated with the statement of Iglesia and co-workers that transition states with more localized charges are less influenced by the Brønsted acid strength than those exhibiting more diffuse charges. ${ }^{147}$ Since the positive charge is more diffuse on benzene due to its conjugated $\pi$-system, the increase of the intrinsic barrier is more significant than for propene. The combined effects explain the more significant effect of LAS incorporation on the intrinsic free energy barrier of benzene methylation compared to propene methylation. Additionally, free energy profiles shown in Figure 10 indicate a destabilization of the product state, for all metal oxide incorporated zeolites. The destabilization can be ascribed to the formation of a carbocation, which is unfavorable near the positively charged alkaline-earth metal cluster as depicted in the reaction schemes in Figure S25 of the SI.

As stated earlier, also mononuclear species can act as a possible LAS after alkaline-earth metal impregnation. In order to be able to compare with their binuclear analogs we investigated the kinetics of the methylation of benzene and propene over the mononuclear $[\mathrm{CaOH}]^{+}$species. Free energy profiles are shown in Figure S29 of the SI. The isolated LAS predicts a significantly higher barrier for both the benzene and propene methylation, suggesting a significantly lower reactivity of these species. Second, the BAS near LAS results for both benzene and propene indicate that the indirect effect of the LAS is less pronounced for the mononuclear case, as the global barrier is closer to the isolated BAS case. We conclude that the influence of mononuclear species on the methylation reactions is less significant than the impact of binuclear species. These conclusions allow us to mainly focus on the binuclear results in this manuscript.

The methylation profiles thus suggest a significant influence of the presence of binuclear Lewis acid sites on the reactivity. To quantify the relative rate of methylation in the neighborhood of a Lewis acid site to the methylation over an isolated BAS, the difference in overall free energy at $500{ }^{\circ} \mathrm{C}$ between the modified active site and an isolated BAS $(\Delta \Delta G)$ is studied. We opt to use the overall free energy barrier rather than the apparent free energy barrier. This would assume that methanol coverage is one, as typically done in kinetic studies on methylation reactions, ${ }^{40,41,141}$ which is not necessarily true at the high temperatures applied in this work $\left(500{ }^{\circ} \mathrm{C}\right)$ as suggested by the positive free energies of adsorption for methanol on the various active sites (vide supra). Correlation plots between the differences in overall free energies and the Lewis acidity characterized by the adsorption enthalpy of pyridine are shown in Figure 13. Furthermore, to enable us to further generalize the conclusions, we also included the results belonging to durene and pseudocumene as an HP reactant representing the aromatic cycle over the alkaline earth metals. Lastly, to finalize all conclusions, the results for the methylation of propene and benzene over the two considered binuclear EFAl species are also included in Figure 13.

The following trends can be deduced from the correlation plots. The methylation of all hydrocarbons is found to be more activated over an isolated alkaline earth metal $[\mathrm{M}(\mu$ $\left.\mathrm{OH})_{2} \mathrm{M}\right]^{2+}$ moiety, leading to relatively high reaction barriers over isolated cationic alkaline-earth metal clusters. An almost linear relation is found between the acidity strength of the LAS and the overall free energy barrier. The EFAl/I species have a much stronger Lewis acidity and may even accelerate the methylation reactions, as is the case for propene. A decrease of $76 \mathrm{~kJ} / \mathrm{mol}$ is observed for the EFAl/I species compared to methylation on a pristine BAS. As discussed in Section 7 of the SI, this can mainly be attributed to the poor stabilization of the $\mathrm{EFAl} / \mathrm{I}$ species by the framework. Most interesting for catalytic purposes is the distinct difference the LAS has on the methylation of benzene compared to propene, except for $\mathrm{EFAl} / \mathrm{II}$. LASs clearly slow down methylation reactions of benzene, which is manifestly confirmed by the methylation of the two other HP species: durene and pseudocumene over alkaline earth metals. Translated to the various catalytic cycles operative in the methanol to olefin process; this means that the aromatic cycle would be suppressed in the LAS incorporated zeolites.

Secondly, it is interesting to study the effect on methylation free energy barriers taking place on a BAS but with proximity of a LAS. The effects on the methylation reactions are much less pronounced for a BAS nearby an LAS. Methylation barriers over a BAS near an $\left[\mathrm{M}(\mu-\mathrm{OH})_{2} \mathrm{M}\right]^{2+}$ moiety $(\square)$ converge to the rate over an isolated BAS with decreased Lewis acid strength of the alkaline earth metaloxide, as the difference in free energy barrier with an isolated BAS becomes smaller 


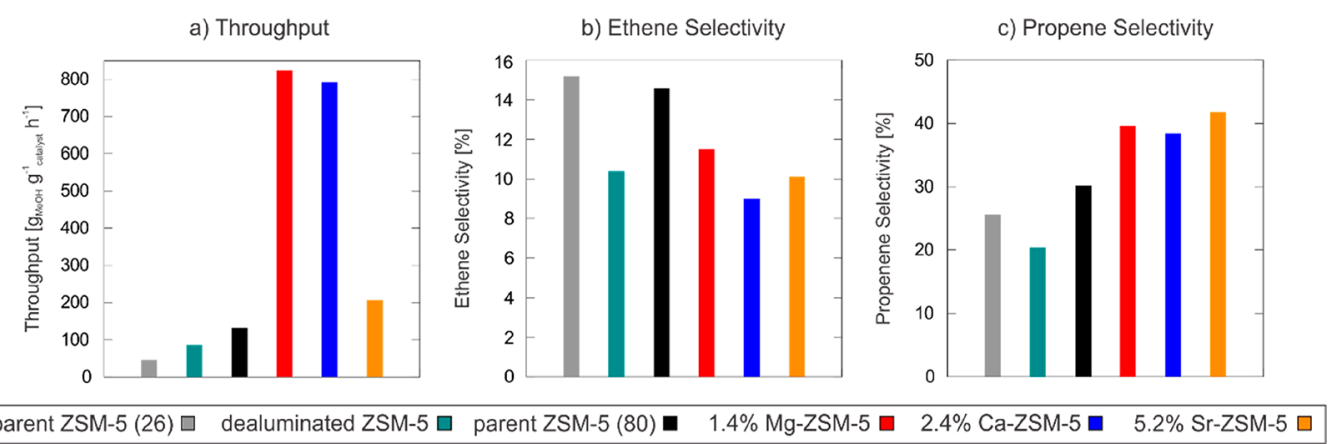

Figure 14. Experimental results obtained at $500{ }^{\circ} \mathrm{C}$ for the throughput (a), selectivity to ethene (b), and selectivity to propene (c) for the MTO reaction over dealuminated ZSM-5 (green), 1.4\% Mg-ZSM-5 (red), 2.4\% Ca-ZSM-5 (blue), and 5.2\% Sr-ZSM-5 (orange) relative to the parent ZSM-5 as a function of the adsorption enthalpy of pyridine. ${ }^{25}$ Results for $8.2 \%$ Ba-ZSM-5 are not reported, as this sample showed a conversion below $5 \%$.

than $10-20 \mathrm{~kJ} / \mathrm{mol}$, which is the typical accuracy of our DFT simulations. ${ }^{3,85}$ Therefore, these differences are assumed to be insignificant. The EFAl species do not follow this trend. Only for BAS/EFAl/I, BAS/EFAl/II, BAS/ $\left[\mathrm{Mg}(\mu-\mathrm{OH})_{2} \mathrm{Mg}\right]^{2+}$, and $\mathrm{BAS} /\left[\mathrm{Ca}(\mu-\mathrm{OH})_{2} \mathrm{Ca}\right]^{2+}$ a significant increase in the free energy methylation barriers is observed. Furthermore, the increase is more pronounced for methylation of benzene compared to propene in the case of EFAl/II, Ca, and $\mathrm{Mg}$ incorporated LASs. While benzene and propene methylation rates only exhibit minor differences on an isolated BAS in $\mathrm{H}$ ZSM-5 (overall free energy barriers of 187 and $197 \mathrm{~kJ} / \mathrm{mol}$ ), the results depicted in Figure 13 suggest that LASs induce an increase in the difference between benzene and propene methylation kinetics over the neighboring BAS. Based on the calculated difference in overall barrier, $\mathrm{Mg}$ and $\mathrm{Ca}$ most selectively decrease benzene methylation rates over a BAS near a $\left[\mathrm{M}(\mu-\mathrm{OH})_{2} \mathrm{M}\right]^{2+}$ moiety, while propene methylation is barely affected on this active site. Methylation of the two other $\mathrm{HP}$ species even reinforces these differences. The introduction of $\mathrm{Sr}$ and $\mathrm{Ba}$ seems to have a limited influence on the neighboring BAS, probably due to their weaker Lewis acidity. Relative free energy differences $\Delta \Delta G$ with respect to the isolated BAS even become negative for durene and pseudocumene. When EFAl species are present, methylation on nearby BASs are substantially more activated, but based on the methylation kinetics on the EFAl/I species itself, it can be concluded that in this case the reactions will preferably occur on the EFAl/I species and also in this case methylations of aromatic species are disfavored.

Previous results suggest that incorporation of LAS sites selectively slow down benzene, durene and pseudocumene methylations, both on isolated LASs as on BASs with proximate LASs. The effect is more pronounced for LASs with stronger acidity. In the latter case the reaction might preferably take place on a pristine LAS rather than on a BAS. Previous findings suggest that incorporation of LAS sites might selectively suppress the aromatic cycle; however, when the Lewis acidity becomes too strong, the BASs might not be the most active sites and reactions might take place on LASs.

As the formation of a carbocation could explain the increased methylation barriers and thus suppression of the aromatic cycle, the stability of some carbocation typical for the aromatic and alkene cycle (see Figure $1 \mathrm{~b}$ ) is assessed using their protonation enthalpy. ${ }^{25}$ Figure $1 \mathrm{~b}$ shows that the aromatic cycle is characterized by cationic six and five ring species, while the alkenes make up the cocatalysts in the alkene cycle. The selection of the aromatic MTO intermediates considered in this paragraph is inspired by the work of Fang and co-workers ${ }^{148}$ in which the most stable carbenium ions in H-ZSM-5 are theoretically predicted extended with other intermediates of both the paring and side-chain mechanism. ${ }^{149}$ To represent the alkene cycle, propene, hexene, and isobutene are selected. For these intermediates, the protonation enthalpy is calculated as defined in our earlier work ${ }^{25}$ and the Computational details. This protonation enthalpy is used as a measure for the stability of the protonated form of the intermediates relative to the neutral species. The more negative this enthalpic value becomes, the more stable the protonated structure becomes. The protonation enthalpy is calculated for each intermediate for both an isolated BAS and on a BAS near a $\left[\mathrm{M}(\mu-\mathrm{OH})_{2} \mathrm{M}\right]^{2+}$ moiety of the considered cationic clusters. As the resulting protonation enthalpies are in line with the results discussed in earlier work, ${ }^{25}$ the interested reader is referred to Section 8 of the Supporting Information for the indepth discussion. The results show a destabilization of the cyclic carbenium ions, while the influence on the alkenes is far less pronounced, suggesting a suppression of the aromatic cycle. ${ }^{25}$ Dealuminated zeolites that follow the trends attributed to Lewis acid strength indicate an improved performance. ${ }^{72,73}$

3.4. Relation between Experimental and Theoretical Findings. Our theoretical results predict incorporation of $\mathrm{Mg}$ or $\mathrm{Ca}$ as the most efficient candidates to suppress the aromatic HP mechanism. Furthermore, our theoretical structural analysis showed that all $\left[\mathrm{M}(\mu-\mathrm{OH})_{2} \mathrm{M}\right]^{2+}$ with $\mathrm{M}=\mathrm{Mg}, \mathrm{Ca}$, $\mathrm{Sr}, \mathrm{Ba}$, or $\mathrm{HOAl}$ are formed at the expense of reducing the number of vicinal BASs. To correlate these findings with experimental observations, catalytic tests were performed on a series of modified ZSM- 5 catalysts. The results for the activity and selectivity experiments as performed in earlier work of the current authors ${ }^{25}$ over the parent and the alkaline-earth metal modified ZSM-5 are depicted in Figure 14. New catalytic tests have been performed on the dealuminated sample extracted from the parent ZSM-5_26. The results for 8.2\% Ba-ZSM-5 are not added to the graphs, as conversion over this catalyst was below $5 \%$, which might be due to blockage of the catalyst pores by the large barium oxide clusters or due to the low Lewis acid strength of this oxide leading to increased reaction barriers (see Figure 13). Furthermore, for the different materials under study, Figure S37 in the SI visualizes the various conversion and yield plots.

The experimental results show two clear trends upon incorporation of LASs. First, Figure 14a shows an increased 
catalyst lifetime upon modification, though the influence seems to depend on the strength of the incorporated Lewis acid sites. These results thus confirm the importance of Lewis acidic characteristics for increased catalyst lifetimes. Second, LAS incorporation leads to an increased selectivity toward propene and decreased selectivity toward ethene. The dealuminated species does not have an increased propene selectivity, but instead an increase in the $\mathrm{C}_{4}$ selectivity is found. Nevertheless, it should be noted that both propene and higher alkenes production are linked to the alkene cycle. This is not surprising since the increased selectivity toward $\mathrm{C}_{3}$ and $\mathrm{C}_{4}$ alkenes is supposed to be ascribed to isolation of BASs by incorporation of LASs. Indeed the incorporation of alkali-earth metal or EFAl species gives rise to a reduction of the number of vicinal BASs, as was discussed in the structural analysis of the metal oxide clusters in Section 2 of the SI. ${ }^{25}$ The lowered BAS density was ascribed to prevent the successive reactions leading to aromatization and coking. ${ }^{25}$

Based on the conversion and yield plots given in Figure S37 of the SI, the role of the LAS additive on the catalyst activity, stability, and selectivity for making propene versus ethene can now easily be derived. The lifetime of the catalyst is drastically increased when the material is doped with $\mathrm{Ca}$ and $\mathrm{Mg}$. The selectivity for propene has increased in the alkaline earth metal modified catalysts compared with their parent ZSM-5_80 zeolite. The selectivity for propene remains constant during the whole active lifecycle $(\sim 100 \mathrm{~h})$ of the modified Ca-catalyst and differs substantially from the parent ZSM-5_80 zeolite which only at the end shows a propene yield of $35 \%$. The other alkaline-earth metals ( $\mathrm{Mg}$ and $\mathrm{Sr}$ ) show a similar behavior to that of their parent material but shifted to higher values of the yields of ethene, propene and butene. Based on these data a clear volcano plot dependency of the catalyst lifetime versus ratio between BAS and LAS is observed (see Figure S36).

The results presented in this work give evidence that LASs suppress the reactivity of methylations of HP species, as demonstrated for benzene, durene, and pseudocumene. Furthermore, intermediates of the aromatic cycle seem to be less stabilized in the LAS modified zeolites. This follows from the protonation enthalpies shown in Figure S31 in the Supporting Information. A significant destabilization of carbocationic, cyclic HP species due to the interaction with any of the neighboring Lewis acid sites is observed, whereas alkene intermediates are less severely affected. Both the increase in methylation barriers of the HP species and decreased stabilization of cyclic carbocations of the aromatic cycle in the LAS modified zeolites give evidence that the aromatic cycle is suppressed with the presence of LASs. Svelle et al. $^{32}$ showed that ethene formation is mechanistically separated from the propene formation. The aromatic cycle is believed to be responsible for ethene formation whereas the alkene cycle yields propene (Figure $1 b$ ). Our theoretical data are thus in line with the experimental findings on increased propene selectivity.

The LAS modified zeolites also show an increased lifetime with respect to their parent material. To date the mechanisms leading to aromatic growth and coke formation are not fully unraveled yet. Various coke mechanisms might be active during methanol conversion. ${ }^{150}$ Our findings here suggest that cyclic carbocations of the aromatic cycle are less stable. The stabilization of the protonated cyclic intermediates will also decrease their reactivity in further coke formation routes. ${ }^{25,35,137}$ Also methylated aromatics are considered as coke precursors, ${ }^{151,152}$ which are less easily formed on LAS modified zeolites due to the increase in methylation barriers of the aromatics. However, to obtain more mechanistic insight into the increased lifetime a comprehensive study including all possible coke aromatics formation routes would have to be conducted, which is beyond the scope of this work.

\section{CONCLUSION}

Understanding the influence of catalyst modification on product selectivity and catalyst lifetime in the methanol-toolefins process is of utmost importance in the optimization of the process toward a flexible propene-on-demand production. Therefore, we investigated the effect of metal containing cations in the zeolites on the nature of the active site, adsorption, and reactivity properties. Both alkaline-earth metal containing oxides as EFAl species were considered. The latter are obtained after dealumination.

The structural analysis of the cationic metal oxide clusters in the zeolite pores showed that introduction of metal oxides enables a reduction of original BASs, since protonation of the bridging free oxygen led to a significant stabilization for all metal oxide species. These extra-framework moieties may be present as mono-, bi-, and/or trinuclear metal complexes. From a theoretical point of view, we find that binuclear $[\mathrm{M}(\mu$ $\left.\mathrm{OH})_{2} \mathrm{M}\right]^{2+}$ species are more stable than mononuclear species. A structural characterization comprising solid state NMR gave indirect evidence for the presence of both monomeric and binuclear species. The acidity characterization of the zeolite modified structures was systematically performed for both mono- and binuclear species and led to consistent results for both types of metal clusters. The newly proposed active sites were shown to possess well-defined Lewis acid sites. This was shown via experimental and theoretical IR spectra for the adsorption of pyridine. An excellent agreement was obtained between theoretical and experimental IR spectra, which gives evidence that our model of the modified active site captures the most important properties and can confidently be used for further kinetic studies. Furthermore, a blue shift in the IR peak characteristic for the LAS was found to correlate linearly with the adsorption enthalpy of pyridine and thus with the Lewis acid strength of the modified active site. This agreement allows the position of the LAS IR peak to be related to the strength of the Lewis acid site, thus creating an experimental tool to check the Lewis acid strength. For the alkaline-earth metal modifications studied, the following acidity scale was found: $\mathrm{Mg}>\mathrm{Ca}>\mathrm{Sr}>\mathrm{Ba}$.

Subsequently, the combined experimental and theoretical analysis of the reactivity properties of modified active sites confirmed the importance of Brønsted acid site isolation and the suppression of the aromatic cycle by the LAS. Experimentally a higher propene selectivity was observed which was most pronounced for the alkaline-earth metal modified zeolites. Furthermore, all LAS modified zeolites show an increased catalyst lifetime with respect to their parent material confirming the conclusions made in earlier work. ${ }^{25}$ All our findings point toward a suppression of the aromatic cycle, as methylation barriers of aromatic HP species are substantially higher on LAS modified zeolites and typical cyclic carbocations are less well stabilized in the presence of additional LASs. The influence on the alkene cycle was rather limited. An optimal combination of catalyst lifetime and propene selectivity was found for the $\mathrm{Mg}$ and $\mathrm{Ca}$ modified zeolites. This could be assigned to a subtle interplay between the influence of the LAS 
on the neighboring BAS and the strength of the LAS itself, as for $\mathrm{Sr}$ and $\mathrm{Ba}$ the weaker LAS is not strong enough to influence the BAS, while for the EFAl species, the strong acidity might make the LAS too reactive on its own. However, the behavior of EFAl species might be strongly dependent on the aluminum positions in the framework. Further investigations are necessary to elucidate the behavior of EFAl species on the catalysis. Our theoretical results show that the impact of mononuclear species is less pronounced on the governing catalytic reactions of the methanol conversion.

Our findings further support the supramolecular concept of the MTO catalyst, which may be tailored at the molecular level. The overall catalyst performance cannot simply be explained using the properties of the BAS but is rather the result of an interplay of the intrinsic zeolite properties, organic compounds, and its proximity to additional LASs. Two opposing effects should be considered when modifying zeolite catalysts with Lewis acid sites. Increased acidic strength of the LAS yields a more pronounced effect on the reactivity of the neighboring BAS, but the LAS itself may become active for catalysis too.

Such modifications together with all other options for tunability such as variability of hydrocarbons, the zeolite channel's dimensions, composition, and acidity support the idea of supramolecular design of the catalyst. It must be emphasized that previous options for modifications may not be regarded independently from each other but introduce an entangled effect on the overall catalyst performance. Design of such a catalyst toward the desired properties may seem extremely challenging; however, more advanced spectroscopic and analysis tools have become available to characterize to a deeper extent the properties of the catalyst. Specifically, for this study pyridine adsorption offered an experimental tool to sample the Lewis acidic strength. The principles of supramolecular catalyst design suggested here may be an inspiration for tuning zeolite catalysts within other application processes.

\section{ASSOCIATED CONTENT}

\section{S Supporting Information}

The Supporting Information is available free of charge on the ACS Publications website at DOI: 10.1021/jacs.9b07484.

Additional computational details on the used ZSM-5 unit cell, Partial Hessian Vibrational Analysis (PHVA), NMR calculations, detailed structural analysis of the Lewis acid sites, additional theoretical vibrational analysis, analysis of the theoretical IR spectrum of adsorbed pyridine, adsorption analysis of methylation reactants on the Lewis acid site, free energy data for the methylation of benzene and propene, results of the calculations of the protonation energy, Cartesian coordinates of the optimized structures obtained from VASP (PDF)

\section{AUTHOR INFORMATION}

\section{Corresponding Authors}

*veronique.vanspeybroeck@ugent.be

*jorge.gascon@kaust.edu.sa

\section{ORCID}

Alexander E. J. Hoffman: 0000-0002-1529-4705

Abhishek Dutta Chowdhury: 0000-0002-4121-7375

Jorge Gascon: 0000-0001-7558-7123

Veronique Van Speybroeck: 0000-0003-2206-178X

\section{Notes}

The authors declare no competing financial interest.

\section{ACKNOWLEDGMENTS}

We acknowledge the Research Foundation - Flanders (FWO), the Research Board of Ghent University (BOF), and funding from the European Union's Horizon 2020 research and innovation program (consolidator ERC Grant Agreement No. 647755 - DYNPOR (2015-2020)). The computational resources and services used were provided by Ghent University (Stevin Supercomputer Infrastructure) and the VSC (Flemish Supercomputer Center), funded by the Research Foundation Flanders (FWO).

\section{REFERENCES}

(1) Zeolites for Cleaner Technologies; Guisnet, M., Gilson, J.-P., Eds.; Catalytic science series; Imperial College Press: London, 2002.

(2) Van Speybroeck, V.; Hemelsoet, K.; Joos, L.; Waroquier, M.; Bell, R. G.; Catlow, C. R. A. Advances in Theory and Their Application within the Field of Zeolite Chemistry. Chem. Soc. Rev. 2015, 44 (20), 7044-7111.

(3) Van Speybroeck, V.; De Wispelaere, K.; Van der Mynsbrugge, J.; Vandichel, M.; Hemelsoet, K.; Waroquier, M. First Principle Chemical Kinetics in Zeolites: The Methanol-to-Olefin Process as a Case Study. Chem. Soc. Rev. 2014, 43 (21), 7326-7357.

(4) Čejka, J.; Centi, G.; Perez-Pariente, J.; Roth, W. J. Zeolite-Based Materials for Novel Catalytic Applications: Opportunities, Perspectives and Open Problems. Catal. Today 2012, 179 (1), 2-15.

(5) Chal, R.; Gérardin, C.; Bulut, M.; van Donk, S. Overview and Industrial Assessment of Synthesis Strategies towards Zeolites with Mesopores. ChemCatChem 2011, 3 (1), 67-81.

(6) Jacobs, P. A.; Dusselier, M.; Sels, B. F. Will Zeolite-Based Catalysis Be as Relevant in Future Biorefineries as in Crude Oil Refineries? Angew. Chem., Int. Ed. 2014, 53 (33), 8621-8626.

(7) Roth, W. J.; Nachtigall, P.; Morris, R. E.; Cejka, J. TwoDimensional Zeolites: Current Status and Perspectives. Chem. Rev. 2014, 114 (9), 4807-4837.

(8) Hemelsoet, K.; Van der Mynsbrugge, J.; De Wispelaere, K.; Waroquier, M.; Van Speybroeck, V. Unraveling the Reaction Mechanisms Governing Methanol-to-Olefins Catalysis by Theory and Experiment. ChemPhysChem 2013, 14 (8), 1526-1545.

(9) Park, Y.-K.; Lee, C. W.; Kang, N. Y.; Choi, W. C.; Choi, S.; Oh, S. H.; Park, D. S. Catalytic Cracking of Lower-Valued Hydrocarbons for Producing Light Olefins. Catal. Surv. Asia 2010, 14 (2), 75-84.

(10) Olsbye, U.; Svelle, S.; Bjørgen, M.; Beato, P.; Janssens, T. V. W.; Joensen, F.; Bordiga, S.; Lillerud, K. P. Conversion of Methanol to Hydrocarbons: How Zeolite Cavity and Pore Size Controls Product Selectivity. Angew. Chem., Int. Ed. 2012, 51 (24), 5810-5831.

(11) Yarulina, I.; Chowdhury, A. D.; Meirer, F.; Weckhuysen, B. M.; Gascon, J. Recent Trends and Fundamental Insights in the Methanolto-Hydrocarbons Process. Nat. Catal. 2018, 1 (6), 398-411.

(12) Dahl, I. M.; Kolboe, S. On the Reaction Mechanism for Hydrocarbon Formation from Methanol over SAPO-34: I. Isotopic Labeling Studies of the Co-Reaction of Ethene and Methanol. J. Catal. 1994, 149 (2), 458-464.

(13) Dahl, I. M.; Kolboe, S. On the Reaction Mechanism for Hydrocarbon Formation from Methanol over SAPO-34:2. Isotopic Labeling Studies of the Co-Reaction of Propene and Methanol. J. Catal. 1996, 161 (1), 304-309.

(14) Dahl, I.; Kolboe, S. On the Reaction-Mechanism for Propene Formation in the MTO Reaction Over SAPO-34. Catal. Lett. 1993, 20 (3-4), 329-336.

(15) Haw, J. F.; Marcus, D. M. Well-Defined (Supra)Molecular Structures in Zeolite Methanol-to-Olefin Catalysis. Top. Catal. 2005, 34 (1-4), 41-48.

(16) Abubakar, S. M.; Marcus, D. M.; Lee, J. C.; Ehresmann, J. O.; Chen, C.-Y.; Kletnieks, P. W.; Guenther, D. R.; Hayman, M. J.; 
Pavlova, M.; Nicholas, J. B.; Haw, J. F. Structural and Mechanistic Investigation of a Phosphate-Modified HZSM-5 Catalyst for Methanol Conversion. Langmuir 2006, 22 (10), 4846-4852.

(17) Derewinski, M.; Sarv, P.; Sun, X.; Müller, S.; van Veen, A. C.; Lercher, J. A. Reversibility of the Modification of HZSM-5 with Phosphate Anions. J. Phys. Chem. C 2014, 118 (12), 6122-6131.

(18) van der Bij, H. E.; Weckhuysen, B. M. Phosphorus Promotion and Poisoning in Zeolite-Based Materials: Synthesis, Characterisation and Catalysis. Chem. Soc. Rev. 2015, 44 (20), 7406-7428.

(19) Klyueva, N. V.; Tien, N. D.; Ione, K. G. Hydrocarbon Synthesis from Methanol on Erionite and Mordenite Catalysts Synthesized in the Presence of $\mathrm{B} 3+, \mathrm{Ga} 3+$ or Fe3+. React. Kinet. Catal. Lett. 1985, 29 (2), 427-432

(20) Esquivel, D.; Cruz-Cabeza, A. J.; Jiménez-Sanchidrián, C.; Romero-Salguero, F. J. Transition Metal Exchanged $\beta$ Zeolites: Characterization of the Metal State and Catalytic Application in the Methanol Conversion to Hydrocarbons. Microporous Mesoporous Mater. 2013, 179 (Supplement C), 30-39.

(21) Dusselier, M.; Deimund, M. A.; Schmidt, J. E.; Davis, M. E. Methanol-to-Olefins Catalysis with Hydrothermally Treated Zeolite SSZ-39. ACS Catal. 2015, 5 (10), 6078-6085.

(22) Van der Borght, K.; Galvita, V. V.; Marin, G. B. Ethanol to Higher Hydrocarbons over Ni, Ga, Fe-Modified ZSM-5: Effect of Metal Content. Appl. Catal., A 2015, 492 (Supplement C), 117-126.

(23) Deimund, M. A.; Harrison, L.; Lunn, J. D.; Liu, Y.; Malek, A.; Shayib, R.; Davis, M. E. Effect of Heteroatom Concentration in SSZ13 on the Methanol-to-Olefins Reaction. ACS Catal. 2016, 6 (2), $542-550$.

(24) Yarulina, I.; Bailleul, S.; Pustovarenko, A.; Martinez, J. R.; De Wispelaere, K.; Hajek, J.; Weckhuysen, B. M.; Houben, K.; Baldus, M.; Van Speybroeck, V.; Kapteijn, F.; Gascon, J. Suppression of the Aromatic Cycle in Methanol-to-Olefins Reaction over ZSM-5 by Post-Synthetic Modification Using Calcium. ChemCatChem 2016, 8 (19), 3057-3063.

(25) Yarulina, I.; De Wispelaere, K.; Bailleul, S.; Goetze, J.; Radersma, M.; Abou-Hamad, E.; Vollmer, I.; Goesten, M.; Mezari, B.; Hensen, E. J. M.; Martínez-Espín, J. S.; Morten, M.; Mitchell, S.; Perez-Ramirez, J.; Olsbye, U.; Weckhuysen, B. M.; Van Speybroeck, V.; Kapteijn, F.; Gascon, J. Structure-Performance Descriptors and the Role of Lewis Acidity in the Methanol-to-Propylene Process. Nat. Chem. 2018, 10 (8), 804-812.

(26) Suzuki, K.; Kiyozumi, Y.; Matsuzaki, K.; Ikai, S.; Shin, S. Effect of Modification of ZSM-5 Type Zeolite with Calcium Phosphate on Its Physico-Chemical and Catalytic Properties. Appl. Catal. 1988, 39, 315-324.

(27) Zhang, S.; Zhang, B.; Gao, Z.; Han, Y. Methanol to Olefin over Ca-Modified HZSM-5 Zeolites. Ind. Eng. Chem. Res. 2010, 49 (5), 2103-2106.

(28) Zhang, S.; Zhang, B.; Gao, Z.; Han, Y. Ca Modified ZSM-5 for High Propylene Selectivity from Methanol. React. Kinet., Mech. Catal. 2010, 99 (2), 447-453.

(29) MAN, J.; ZHANG, Q.; XIE, H.; PAN, J.; TAN, Y.; HAN, Y. Effects of Reaction Atmosphere on Dimethyl Ether Conversion to Propylene Process over Ca/ZSM-5. J. Fuel Chem. Technol. 2011, 39 (1), 42-46.

(30) Chen, C.; Zhang, Q.; Meng, Z.; Li, C.; Shan, H. Effect of Magnesium Modification over H-ZSM-5 in Methanol to Propylene Reaction. Appl. Petrochem. Res. 2015, 5 (4), 277-284.

(31) Sun, X.; Mueller, S.; Liu, Y.; Shi, H.; Haller, G. L.; SanchezSanchez, M.; van Veen, A. C.; Lercher, J. A. On Reaction Pathways in the Conversion of Methanol to Hydrocarbons on HZSM-5. J. Catal. 2014, 317, 185-197.

(32) Svelle, S.; Joensen, F.; Nerlov, J.; Olsbye, U.; Lillerud, K.-P.; Kolboe, S.; Bjørgen, M. Conversion of Methanol into Hydrocarbons over Zeolite H-ZSM-5: Ethene Formation Is Mechanistically Separated from the Formation of Higher Alkenes. J. Am. Chem. Soc. 2006, 128 (46), 14770-14771.

(33) De Wispelaere, K.; Bailleul, S.; Van Speybroeck, V. Towards Molecular Control of Elementary Reactions in Zeolite Catalysis by
Advanced Molecular Simulations Mimicking Operating Conditions. Catal. Sci. Technol. 2016, 6 (8), 2686-2705.

(34) Van Speybroeck, V.; Hemelsoet, K.; De Wispelaere, K.; Qian, Q.; Van der Mynsbrugge, J.; De Sterck, B.; Weckhuysen, B. M.; Waroquier, M. Mechanistic Studies on Chabazite-Type Methanol-toOlefin Catalysts: Insights from Time-Resolved UV/Vis Microspectroscopy Combined with Theoretical Simulations. ChemCatChem 2013, 5 (1), 173-184.

(35) Hemelsoet, K.; Qian, Q.; De Meyer, T.; De Wispelaere, K.; De Sterck, B.; Weckhuysen, B. M.; Waroquier, M.; Van Speybroeck, V. Identification of Intermediates in Zeolite-Catalyzed Reactions by In Situ UV/Vis Microspectroscopy and a Complementary Set of Molecular Simulations. Chem. - Eur. J. 2013, 19 (49), 16595-16606.

(36) De Wispelaere, K.; Hemelsoet, K.; Waroquier, M.; Van Speybroeck, V. Complete Low-Barrier Side-Chain Route for Olefin Formation during Methanol Conversion in H-SAPO-34. J. Catal. 2013, 305, 76-80.

(37) Lesthaeghe, D.; De Sterck, B.; Van Speybroeck, V.; Marin, G. B.; Waroquier, M. Zeolite Shape-Selectivity in the Gem-Methylation of Aromatic Hydrocarbons. Angew. Chem., Int. Ed. 2007, 46 (8), $1311-1314$

(38) McCann, D. M.; Lesthaeghe, D.; Kletnieks, P. W.; Guenther, D. R.; Hayman, M. J.; Van Speybroeck, V.; Waroquier, M.; Haw, J. F. A Complete Catalytic Cycle for Supramolecular Methanol-to-Olefins Conversion by Linking Theory with Experiment. Angew. Chem., Int. Ed. 2008, 47 (28), 5179-5182.

(39) Wang, C.-M.; Wang, Y.-D.; Xie, Z.-K.; Liu, Z.-P. Methanol to Olefin Conversion on HSAPO-34 Zeolite from Periodic Density Functional Theory Calculations: A Complete Cycle of Side Chain Hydrocarbon Pool Mechanism. J. Phys. Chem. C 2009, 113 (11), 4584-4591.

(40) Svelle, S.; Rønning, P. O.; Kolboe, S. Kinetic Studies of ZeoliteCatalyzed Methylation Reactions: 1 . Coreaction of [12C]Ethene and [13C]Methanol. J. Catal. 2004, 224 (1), 115-123.

(41) Svelle, S.; Rønning, P. O.; Olsbye, U.; Kolboe, S. Kinetic Studies of Zeolite-Catalyzed Methylation Reactions. Part 2. CoReaction of [12C]Propene or [12C]n-Butene and [13C $]$ Methanol. J. Catal. 2005, 234 (2), 385-400.

(42) Lesthaeghe, D.; Van der Mynsbrugge, J.; Vandichel, M.; Waroquier, M.; Van Speybroeck, V. Full Theoretical Cycle for Both Ethene and Propene Formation during Methanol-to-Olefin Conversion in H-ZSM-5. ChemCatChem 2011, 3 (1), 208-212.

(43) Lin, B.; Zhang, Q.; Wang, Y. Catalytic Conversion of Ethylene to Propylene and Butenes over H-ZSM-5. Ind. Eng. Chem. Res. 2009, 48 (24), 10788-10795.

(44) Takahashi, A.; Xia, W.; Wu, Q.; Furukawa, T.; Nakamura, I.; Shimada, H.; Fujitani, T. Difference between the Mechanisms of Propylene Production from Methanol and Ethanol over ZSM-5 Catalysts. Appl. Catal., A 2013, 467, 380-385.

(45) Zhang, H.; Ning, Z.; Shang, J.; Liu, H.; Han, S.; Qu, W.; Jiang, Y.; Guo, Y. A Durable and Highly Selective PbO/HZSM-5 Catalyst for Methanol to Propylene (MTP) Conversion. Microporous Mesoporous Mater. 2017, 248, 173-178.

(46) Prakash, N.; Lee, M.-H.; Yoon, S.; Jung, K.-D. Role of Acid Solvent to Prepare Highly Active PtSn/ $\theta-\mathrm{Al} 2 \mathrm{O} 3$ Catalysts in Dehydrogenation of Propane to Propylene. Catal. Today 2017, 293, 33-41.

(47) Sun, X.; Mueller, S.; Shi, H.; Haller, G. L.; Sanchez-Sanchez, M.; van Veen, A. C.; Lercher, J. A. On the Impact of Co-Feeding Aromatics and Olefins for the Methanol-to-Olefins Reaction on HZSM-5. J. Catal. 2014, 314, 21-31.

(48) Teketel, S.; Svelle, S.; Lillerud, K.-P.; Olsbye, U. ShapeSelective Conversion of Methanol to Hydrocarbons Over 10-Ring Unidirectional-Channel Acidic H-ZSM-22. ChemCatChem 2009, 1 (1), 78-81.

(49) Teketel, S.; Olsbye, U.; Lillerud, K.-P.; Beato, P.; Svelle, S. Selectivity Control through Fundamental Mechanistic Insight in the Conversion of Methanol to Hydrocarbons over Zeolites. Microporous Mesoporous Mater. 2010, 136 (1-3), 33-41. 
(50) Hereijgers, B. P. C.; Bleken, F.; Nilsen, M. H.; Svelle, S.; Lillerud, K.-P.; Bjørgen, M.; Weckhuysen, B. M.; Olsbye, U. Product Shape Selectivity Dominates the Methanol-to-Olefins (MTO) Reaction over H-SAPO-34 Catalysts. J. Catal. 2009, 264 (1), 77-87. (51) Westgård Erichsen, M.; Svelle, S.; Olsbye, U. H-SAPO-5 as Methanol-to-Olefins (MTO) Model Catalyst: Towards Elucidating the Effects of Acid Strength. J. Catal. 2013, 298, 94-101.

(52) Westgård Erichsen, M.; Svelle, S.; Olsbye, U. The Influence of Catalyst Acid Strength on the Methanol to Hydrocarbons (MTH) Reaction. Catal. Today 2013, 215, 216-223.

(53) Westgård Erichsen, M.; De Wispelaere, K.; Hemelsoet, K.; Moors, S. L. C.; Deconinck, T.; Waroquier, M.; Svelle, S.; Van Speybroeck, V.; Olsbye, U. How Zeolitic Acid Strength and Composition Alter the Reactivity of Alkenes and Aromatics towards Methanol. J. Catal. 2015, 328, 186-196.

(54) Svelle, S.; Olsbye, U.; Joensen, F.; Bjørgen, M. Conversion of Methanol to Alkenes over Medium- and Large-Pore Acidic Zeolites: Steric Manipulation of the Reaction Intermediates Governs the Ethene/Propene Product Selectivity. J. Phys. Chem. C 2007, 111 (49), 17981-17984.

(55) Bjørgen, M.; Joensen, F.; Lillerud, K.-P.; Olsbye, U.; Svelle, S. The Mechanisms of Ethene and Propene Formation from Methanol over High Silica H-ZSM-5 and H-Beta. Catal. Today 2009, 142 (12), 90-97.

(56) Bjørgen, M.; Akyalcin, S.; Olsbye, U.; Benard, S.; Kolboe, S.; Svelle, S. Methanol to Hydrocarbons over Large Cavity Zeolites: Toward a Unified Description of Catalyst Deactivation and the Reaction Mechanism. J. Catal. 2010, 275 (1), 170-180.

(57) Bjørgen, M.; Olsbye, U.; Petersen, D.; Kolboe, S. The Methanol-to-Hydrocarbons Reaction: Insight into the Reaction Mechanism from [12C]Benzene and [13C]Methanol Coreactions over Zeolite H-Beta. J. Catal. 2004, 221 (1), 1-10.

(58) Ahn, J. H.; Temel, B.; Iglesia, E. Selective Homologation Routes to 2,2,3-Trimethylbutane on Solid Acids. Angew. Chem., Int. Ed. 2009, 48 (21), 3814-3816.

(59) Simonetti, D. A.; Ahn, J. H.; Iglesia, E. Mechanistic Details of Acid-Catalyzed Reactions and Their Role in the Selective Synthesis of Triptane and Isobutane from Dimethyl Ether. J. Catal. 2011, 277 (2), 173-195.

(60) Koempel, H.; Liebner, W. Lurgi's Methanol To Propylene (MTP) Report on a Successful Commercialisation. In Studies in Surface Science and Catalysis; Noronha, F. B., Schmal, M., SousaAguiar, E. F., Eds.; Natural Gas Conversion VIII Proceedings of the 8th Natural Gas Conversion Symposium; Elsevier: 2007; Vol. 167, pp 261-267.

(61) Kosinov, N.; Liu, C.; Hensen, E. J. M.; Pidko, E. A. Engineering of Transition Metal Catalysts Confined in Zeolites. Chem. Mater. 2018, 30 (10), 3177-3198.

(62) Zheng, H.; Ma, D.; Bao, X.; Hu, J. Z.; Kwak, J. H.; Wang, Y.; Peden, C. H. F. Direct Observation of the Active Center for Methane Dehydroaromatization Using an Ultrahigh Field 95Mo NMR Spectroscopy. J. Am. Chem. Soc. 2008, 130 (12), 3722-3723.

(63) Beyer, H. K. Dealumination Techniques for Zeolites. PostSynthesis Modification I; Molecular Sieves; Springer: Berlin, Heidelberg, 2002; pp 203-255.

(64) Jin, L.; Hu, H.; Zhu, S.; Ma, B. An Improved Dealumination Method for Adjusting Acidity of HZSM-5. Catal. Today 2010, 149 (1), 207-211.

(65) Liu, C.; Li, G.; Hensen, E. J. M.; Pidko, E. A. Nature and Catalytic Role of Extraframework Aluminum in Faujasite Zeolite: A Theoretical Perspective. ACS Catal. 2015, 5 (11), 7024-7033.

(66) Dyballa, M.; Becker, P.; Trefz, D.; Klemm, E.; Fischer, A.; Jakob, H.; Hunger, M. Parameters Influencing the Selectivity to Propene in the MTO Conversion on 10-Ring Zeolites: Directly Synthesized Zeolites ZSM-5, ZSM-11, and ZSM-22. Appl. Catal., A 2016, 510 (Supplement C), 233-243.

(67) Jabbari, A.; Abbasi, A.; Zargarnezhad, H.; Riazifar, M. A Study on the Effect of SiO2/Al2O3 Ratio on the Structure and Performance of Nano-Sized ZSM-5 in Methanol to Propylene Conversion. React. Kinet., Mech. Catal. 2017, 121 (2), 763-772.

(68) Dai, W.; Cao, G.; Yang, L.; Wu, G.; Dyballa, M.; Hunger, M.; Guan, N.; Li, L. Insights into the Catalytic Cycle and Activity of Methanol-to-Olefin Conversion over Low-Silica AlPO-34 Zeolites with Controllable Brønsted Acid Density. Catal. Sci. Technol. 2017, 7 (3), 607-618.

(69) Rostamizadeh, M.; Yaripour, F. Dealumination of High Silica H-ZSM-5 as Long-Lived Nanocatalyst for Methanol to Olefin Conversion. J. Taiwan Inst. Chem. Eng. 2017, 71, 454-463.

(70) Kong, C.; Zhu, J.; Liu, S.; Wang, Y. SAPO-34 with a Low Acidity Outer Layer by Epitaxial Growth and Its Improved MTO Performance. RSC Adv. 2017, 7 (63), 39889-39898.

(71) Stöcker, M. Methanol-to-Hydrocarbons: Catalytic Materials and Their Behavior. Microporous Mesoporous Mater. 1999, 29 (1-2), $3-48$.

(72) Mei, C.; Wen, P.; Liu, Z.; Liu, H.; Wang, Y.; Yang, W.; Xie, Z.; Hua, W.; Gao, Z. Selective Production of Propylene from Methanol: Mesoporosity Development in High Silica HZSM-5. J. Catal. 2008, 258 (1), 243-249.

(73) Milina, M.; Mitchell, S.; Michels, N.-L.; Kenvin, J.; PérezRamírez, J. Interdependence between Porosity, Acidity, and Catalytic Performance in Hierarchical ZSM-5 Zeolites Prepared by PostSynthetic Modification. J. Catal. 2013, 308, 398-407.

(74) Brus, J.; Kobera, L.; Schoefberger, W.; Urbanová, M.; Klein, P.; Sazama, P.; Tabor, E.; Sklenak, S.; Fishchuk, A. V.; Dědeček, J. Structure of Framework Aluminum Lewis Sites and Perturbed Aluminum Atoms in Zeolites as Determined by $27 \mathrm{Al}\{1 \mathrm{H}\}$ REDOR (3Q) MAS NMR Spectroscopy and DFT/Molecular Mechanics. Angew. Chem., Int. Ed. 2015, 54 (2), 541-545.

(75) Zhang, L.; Wang, H.; Liu, G.; Gao, K.; Wu, J. Methanol-toOlefin Conversion over H-MCM-22 Catalyst. J. Mol. Catal. A: Chem. 2016, 411, 311-316.

(76) Zhang, L.; Wang, H.; Liu, G.; Gao, K.; Wu, J. Conversion of Methanol to Light Olefins over H-MCM-22 Dealuminated with Different Methods. J. Chem. Technol. Biotechnol. 2017, 92 (6), 13531361.

(77) Kresse, G.; Hafner, J. Ab Initio Molecular Dynamics for Liquid Metals. Phys. Rev. B: Condens. Matter Mater. Phys. 1993, 47 (1), 558561.

(78) Kresse, G.; Hafner, J. Ab Initio Molecular-Dynamics Simulation of the Liquid-Metal Amorphous-Semiconductor Transition in Germanium. Phys. Rev. B: Condens. Matter Mater. Phys. 1994, 49 (20), 14251-14269.

(79) Kresse, G.; Furthmüller, J. Efficiency of Ab-Initio Total Energy Calculations for Metals and Semiconductors Using a Plane-Wave Basis Set. Comput. Mater. Sci. 1996, 6 (1), 15-50.

(80) Kresse, G.; Furthmüller, J. Efficient Iterative Schemes for Ab Initio Total-Energy Calculations Using a Plane-Wave Basis Set. Phys. Rev. B: Condens. Matter Mater. Phys. 1996, 54 (16), 11169-11186.

(81) Perdew, J. P.; Burke, K.; Ernzerhof, M. Generalized Gradient Approximation Made Simple. Phys. Rev. Lett. 1996, 77 (18), 38653868.

(82) Grimme, S.; Antony, J.; Ehrlich, S.; Krieg, H. A Consistent and Accurate Ab Initio Parametrization of Density Functional Dispersion Correction (DFT-D) for the 94 Elements H-Pu. J. Chem. Phys. 2010, 132 (15), 154104.

(83) Hajek, J.; Van der Mynsbrugge, J.; De Wispelaere, K.; Cnudde, P.; Vanduyfhuys, L.; Waroquier, M.; Van Speybroeck, V. On the Stability and Nature of Adsorbed Pentene in Brønsted Acid Zeolite H-ZSM-5 at 323 K. J. Catal. 2016, 340, 227-235.

(84) Svelle, S.; Tuma, C.; Rozanska, X.; Kerber, T.; Sauer, J. Quantum Chemical Modeling of Zeolite-Catalyzed Methylation Reactions: Toward Chemical Accuracy for Barriers. J. Am. Chem. Soc. 2009, 131 (2), 816-825.

(85) Piccini, G.; Alessio, M.; Sauer, J. Ab Initio Calculation of Rate Constants for Molecule-Surface Reactions with Chemical Accuracy. Angew. Chem., Int. Ed. 2016, 55 (17), 5235-5237. 
(86) Tuma, C.; Sauer, J. Treating Dispersion Effects in Extended Systems by Hybrid MP2:DFT Calculations-Protonation of Isobutene in Zeolite Ferrierite. Phys. Chem. Chem. Phys. 2006, 8 (34), 3955-3965.

(87) Tuma, C.; Kerber, T.; Sauer, J. The Tert-Butyl Cation in HZeolites: Deprotonation to Isobutene and Conversion into Surface Alkoxides. Angew. Chem., Int. Ed. 2010, 49 (27), 4678-4680.

(88) Hansen, N.; Kerber, T.; Sauer, J.; Bell, A. T.; Keil, F. J. Quantum Chemical Modeling of Benzene Ethylation over H-ZSM-5 Approaching Chemical Accuracy: A Hybrid MP2:DFT Study. J. Am. Chem. Soc. 2010, 132 (33), 11525-11538.

(89) Rybicki, M.; Sauer, J. Ab Initio Prediction of Proton Exchange Barriers for Alkanes at Brønsted Sites of Zeolite H-MFI. J. Am. Chem. Soc. 2018, 140 (51), 18151-18161.

(90) Goncalves, T. J.; Plessow, P. N.; Studt, F. On the Accuracy of Density Functional Theory in Zeolite Catalysis. ChemCatChem 2019, $11,1-10$.

(91) Blöchl, P. E. Projector Augmented-Wave Method. Phys. Rev. B: Condens. Matter Mater. Phys. 1994, 50 (24), 17953-17979.

(92) Kresse, G.; Joubert, D. From Ultrasoft Pseudopotentials to the Projector Augmented-Wave Method. Phys. Rev. B: Condens. Matter Mater. Phys. 1999, 59 (3), 1758-1775.

(93) Heyden, A.; Bell, A. T.; Keil, F. J. Efficient Methods for Finding Transition States in Chemical Reactions: Comparison of Improved Dimer Method and Partitioned Rational Function Optimization Method. J. Chem. Phys. 2005, 123 (22), 224101.

(94) Pulay, P. Convergence Acceleration of Iterative Sequences. the Case of Scf Iteration. Chem. Phys. Lett. 1980, 73 (2), 393-398.

(95) Press, W. H.; Flannery, B. P.; Teukolsky, S. A.; Vetterling, W. T. Numerical Recipes: The Art of Scientific Computing; Cambridge Univ. Press: New York, 1986.

(96) De Moor, B. A.; Ghysels, A.; Reyniers, M.-F.; Van Speybroeck, V.; Waroquier, M.; Marin, G. B. Normal Mode Analysis in Zeolites: Toward an Efficient Calculation of Adsorption Entropies. J. Chem. Theory Comput. 2011, 7 (4), 1090-1101.

(97) Ghysels, A.; Verstraelen, T.; Hemelsoet, K.; Waroquier, M.; Van Speybroeck, V. TAMkin: A Versatile Package for Vibrational Analysis and Chemical Kinetics. J. Chem. Inf. Model. 2010, 50 (9), $1736-1750$

(98) De Moor, B. A.; Reyniers, M.-F.; Marin, G. B. Physisorption and Chemisorption of Alkanes and Alkenes in H-FAU: A Combined Ab Initio-Statistical Thermodynamics Study. Phys. Chem. Chem. Phys. 2009, 11 (16), 2939-2958.

(99) Martinez-Espin, J. S.; De Wispelaere, K.; Westgård Erichsen, M.; Svelle, S.; Janssens, T. V. W.; Van Speybroeck, V.; Beato, P.; Olsbye, U. Benzene Co-Reaction with Methanol and Dimethyl Ether over Zeolite and Zeotype Catalysts: Evidence of Parallel Reaction Paths to Toluene and Diphenylmethane. J. Catal. 2017, 349, 136148.

(100) Baroni, S.; de Gironcoli, S.; Dal Corso, A.; Giannozzi, P. Phonons and Related Crystal Properties from Density-Functional Perturbation Theory. Rev. Mod. Phys. 2001, 73 (2), 515-562.

(101) Wu, X.; Vanderbilt, D.; Hamann, D. R. Systematic Treatment of Displacements, Strains, and Electric Fields in Density-Functional Perturbation Theory. Phys. Rev. B: Condens. Matter Mater. Phys. 2005, 72 (3), 035105.

(102) Gajdoš, M.; Hummer, K.; Kresse, G.; Furthmüller, J.; Bechstedt, F. Linear Optical Properties in the Projector-Augmented Wave Methodology. Phys. Rev. B: Condens. Matter Mater. Phys. 2006, 73 (4), 045112.

(103) Karhánek, D.; Bučko, T.; Hafner, J. A Density-Functional Study of the Adsorption of Methane-Thiol on the (111) Surfaces of the Ni-Group Metals: II. Vibrational Spectroscopy. J. Phys.: Condens. Matter 2010, 22 (26), 265006.

(104) Hoffman, A. E. J.; Vanduyfhuys, L.; Nevjestić, I.; Wieme, J.; Rogge, S. M. J.; Depauw, H.; Van Der Voort, P.; Vrielinck, H.; Van Speybroeck, V. Elucidating the Vibrational Fingerprint of the Flexible Metal-Organic Framework MIL-53(Al) Using a Combined Exper-
imental/Computational Approach. J. Phys. Chem. C 2018, 122 (5), 2734-2746.

(105) Laury, M. L.; Carlson, M. J.; Wilson, A. K. Vibrational Frequency Scale Factors for Density Functional Theory and the Polarization Consistent Basis Sets. J. Comput. Chem. 2012, 33 (30), $2380-2387$.

(106) Merrick, J. P.; Moran, D.; Radom, L. An Evaluation of Harmonic Vibrational Frequency Scale Factors. J. Phys. Chem. A 2007, 111 (45), 11683-11700.

(107) Pickard, C. J.; Mauri, F. All-Electron Magnetic Response with Pseudopotentials: NMR Chemical Shifts. Phys. Rev. B: Condens. Matter Mater. Phys. 2001, 63 (24), 245101.

(108) Hutter, J.; Iannuzzi, M.; Schiffmann, F.; VandeVondele, J. Cp2k: Atomistic Simulations of Condensed Matter Systems. Wiley Interdiscip. Rev. Comput. Mol. Sci. 2014, 4 (1), 15-25.

(109) VandeVondele, J.; Krack, M.; Mohamed, F.; Parrinello, M.; Chassaing, T.; Hutter, J. Quickstep: Fast and Accurate Density Functional Calculations Using a Mixed Gaussian and Plane Waves Approach. Comput. Phys. Commun. 2005, 167 (2), 103-128.

(110) Emeis, C. A. Determination of Integrated Molar Extinction Coefficients for Infrared Absorption Bands of Pyridine Adsorbed on Solid Acid Catalysts. J. Catal. 1993, 141 (2), 347-354.

(111) Pidko, E. A.; Hensen, E. J. M.; van Santen, R. A. SelfOrganization of Extraframework Cations in Zeolites. Proc. R. Soc. London, Ser. A 2012, 468 (2143), 2070-2086.

(112) Pidko, E. A.; Hensen, E. J. M.; Zhidomirov, G. M.; van Santen, R. A. Non-Localized Charge Compensation in Zeolites: A Periodic DFT Study of Cationic Gallium-Oxide Clusters in Mordenite. J. Catal. 2008, 255 (2), 139-143.

(113) Pidko, E. A.; van Santen, R. A.; Hensen, E. J. M. Multinuclear Gallium-Oxide Cations in High-Silica Zeolites. Phys. Chem. Chem. Phys. 2009, 11 (16), 2893-2902.

(114) Li, G.; Pidko, E. A.; van Santen, R. A.; Feng, Z.; Li, C.; Hensen, E. J. M. Stability and Reactivity of Active Sites for Direct Benzene Oxidation to Phenol in Fe/ZSM-5: A Comprehensive Periodic DFT Study. J. Catal. 2011, 284 (2), 194-206.

(115) Li, G.; Pidko, E. A.; van Santen, R. A.; Li, C.; Hensen, E. J. M. Stability of Extraframework Iron-Containing Complexes in ZSM-5 Zeolite. J. Phys. Chem. C 2013, 117 (1), 413-426.

(116) Li, G.; Pidko, E. A.; Filot, I. A. W.; van Santen, R. A.; Li, C.; Hensen, E. J. M. Catalytic Properties of Extraframework IronContaining Species in ZSM-5 for N2O Decomposition. J. Catal. 2013, 308, 386-397.

(117) Knott, B. C.; Nimlos, C. T.; Robichaud, D. J.; Nimlos, M. R.; Kim, S.; Gounder, R. Consideration of the Aluminum Distribution in Zeolites in Theoretical and Experimental Catalysis Research. ACS Catal. 2018, 8 (2), 770-784.

(118) Dib, E.; Mineva, T.; Veron, E.; Sarou-Kanian, V.; Fayon, F.; Alonso, B. ZSM-5 Zeolite: Complete Al Bond Connectivity and Implications on Structure Formation from Solid-State NMR and Quantum Chemistry Calculations. J. Phys. Chem. Lett. 2018, 9 (1), 19-24.

(119) Holzinger, J.; Nielsen, M.; Beato, P.; Brogaard, R. Y.; Buono, C.; Dyballa, M.; Falsig, H.; Skibsted, J.; Svelle, S. Identification of Distinct Framework Aluminum Sites in Zeolite ZSM-23: A Combined Computational and Experimental 27Al NMR Study. J. Phys. Chem. C 2019, 123 (13), 7831-7844.

(120) Bryce, D. L. Calcium Binding Environments Probed by 43Ca NMR Spectroscopy. Dalton Trans 2010, 39 (37), 8593-8602.

(121) Aebi, D.; Bultz, E. B.; Bryce, D. L. Calcium-43 Chemical Shift Tensors as Probes of Calcium Binding Environments. Insight into the Structure of the Vaterite $\mathrm{CaCO} 3$ Polymorph by 43Ca Solid-State NMR Spectroscopy. J. Am. Chem. Soc. 2008, 130 (29), 9282-9292.

(122) Lee, D.; Leroy, C.; Crevant, C.; Bonhomme-Coury, L.; Babonneau, F.; Laurencin, D.; Bonhomme, C.; De Paëpe, G. Interfacial Ca2+ Environments in Nanocrystalline Apatites Revealed by Dynamic Nuclear Polarization Enhanced 43Ca NMR Spectroscopy. Nat. Commun. 2017, 8, 14104. 
(123) Jiang, Y.; Huang, J.; Dai, W.; Hunger, M. Solid-State Nuclear Magnetic Resonance Investigations of the Nature, Property, and Activity of Acid Sites on Solid Catalysts. Solid State Nucl. Magn. Reson. 2011, 39 (3), 116-141.

(124) Derouane, E. G.; Védrine, J. C.; Pinto, R. R.; Borges, P. M.; Costa, L.; Lemos, M. A. N. D. A.; Lemos, F.; Ribeiro, F. R. The Acidity of Zeolites: Concepts, Measurements and Relation to Catalysis: A Review on Experimental and Theoretical Methods for the Study of Zeolite Acidity. Catal. Rev.: Sci. Eng. 2013, 55 (4), 454515 .

(125) Zheng, A.; Liu, S.-B.; Deng, F. Acidity Characterization of Heterogeneous Catalysts by Solid-State NMR Spectroscopy Using Probe Molecules. Solid State Nucl. Magn. Reson. 2013, 55 (Supplement C), 12-27.

(126) Hadjiivanov, K. Chapter Two - Identification and Characterization of Surface Hydroxyl Groups by Infrared Spectroscopy. In Advances in Catalysis; Jentoft, F. C., Ed.; Academic Press: 2014; Vol. 57, pp 99-318.

(127) Sandoval-Díaz, L.-E.; González-Amaya, J.-A.; Trujillo, C.-A. General Aspects of Zeolite Acidity Characterization. Microporous Mesoporous Mater. 2015, 215 (Supplement C), 229-243.

(128) Parry, E. P. An Infrared Study of Pyridine Adsorbed on Acidic Solids. Characterization of Surface Acidity. J. Catal. 1963, 2 (5), 371379.

(129) Velthoen, M. E. Z.; Nab, S.; Weckhuysen, B. M. Probing Acid Sites in Solid Catalysts with Pyridine UV-Vis Spectroscopy. Phys. Chem. Chem. Phys. 2018, 20 (33), 21647-21659.

(130) Cannings, F. R. Acidic Sites on Mordenite: An Infrared Study of Adsorbed Pyridine. J. Phys. Chem. 1968, 72 (13), 4691-4693.

(131) Barzetti, T.; Selli, E.; Moscotti, D.; Forni, L. Pyridine and Ammonia as Probes for FTIR Analysis of Solid Acid Catalysts. J. Chem. Soc., Faraday Trans. 1996, 92 (8), 1401-1407.

(132) Meloni, D.; Laforge, S.; Martin, D.; Guisnet, M.; Rombi, E.; Solinas, V. Acidic and Catalytic Properties of H-MCM-22 Zeolites. Appl. Catal., A 2001, 215 (1), 55-66.

(133) Nishi, K.; Kamiya, N.; Yokomori, Y. Single-Crystal Structure of a Pyridine Sorption Complex of Zeolite HZSM-5 (H-MFI). Microporous Mesoporous Mater. 2007, 101 (1-2), 83-89.

(134) Zhang, L.; Gao, J.; Hu, J.; Li, W.; Wang, J. Lanthanum OxidesImproved Catalytic Performance of ZSM-5 in Toluene Alkylation with Methanol. Catal. Lett. 2009, 130 (3-4), 355-361.

(135) Sartipi, S.; Parashar, K.; Valero-Romero, M. J.; Santos, V. P.; van der Linden, B.; Makkee, M.; Kapteijn, F.; Gascon, J. Hierarchical H-ZSM-5-Supported Cobalt for the Direct Synthesis of GasolineRange Hydrocarbons from Syngas: Advantages, Limitations, and Mechanistic Insight. J. Catal. 2013, 305, 179-190.

(136) Boscoboinik, J. A.; Yu, X.; Emmez, E.; Yang, B.; Shaikhutdinov, S.; Fischer, F. D.; Sauer, J.; Freund, H.-J. Interaction of Probe Molecules with Bridging Hydroxyls of Two-Dimensional Zeolites: A Surface Science Approach. J. Phys. Chem. C 2013, 117 (26), 13547-13556.

(137) Nicholas, J. B.; Haw, J. F. The Prediction of Persistent Carbenium Ions in Zeolites. J. Am. Chem. Soc. 1998, 120 (45), 11804-11805.

(138) Peña, L. F. G.; Sad, M. E.; Padró, C. L.; Apesteguía, C. R. Study of the Alkylation of Phenol with Methanol on $\mathrm{Zn}(\mathrm{H})$ Exchanged NaY Zeolites. Catal. Lett. 2011, 141 (7), 939-947.

(139) Li, X.; Lu, J.; Li, Y.; Yu, J. Roles of Hydroxyl Groups During Side-Chain Alkylation of Toluene with Methanol over Zeolite Na-Y: A Density Functional Theory Study. Chin. J. Chem. 2017, 35 (5), $716-722$.

(140) Van Speybroeck, V.; Van der Mynsbrugge, J.; Vandichel, M.; Hemelsoet, K.; Lesthaeghe, D.; Ghysels, A.; Marin, G. B.; Waroquier, M. First Principle Kinetic Studies of Zeolite-Catalyzed Methylation Reactions. J. Am. Chem. Soc. 2011, 133 (4), 888-899.

(141) Van der Mynsbrugge, J.; Visur, M.; Olsbye, U.; Beato, P.; Bjørgen, M.; Van Speybroeck, V.; Svelle, S. Methylation of Benzene by Methanol: Single-Site Kinetics over H-ZSM-5 and H-Beta Zeolite Catalysts. J. Catal. 2012, 292, 201-212.
(142) Van der Mynsbrugge, J.; Moors, S. L. C.; De Wispelaere, K.; Van Speybroeck, V. Insight into the Formation and Reactivity of Framework-Bound Methoxide Species in H-ZSM-5 from Static and Dynamic Molecular Simulations. ChemCatChem 2014, 6 (7), 19061918.

(143) Van der Mynsbrugge, J.; Hemelsoet, K.; Vandichel, M.; Waroquier, M.; Van Speybroeck, V. Efficient Approach for the Computational Study of Alcohol and Nitrile Adsorption in H-ZSM-5. J. Phys. Chem. C 2012, 116 (9), 5499-5508.

(144) Cnudde, P.; De Wispelaere, K.; Van der Mynsbrugge, J.; Waroquier, M.; Van Speybroeck, V. Effect of Temperature and Branching on the Nature and Stability of Alkene Cracking Intermediates in H-ZSM-5. J. Catal. 2017, 345, 53-69.

(145) Moors, S. L. C.; De Wispelaere, K.; Van der Mynsbrugge, J.; Waroquier, M.; Van Speybroeck, V. Molecular Dynamics Kinetic Study on the Zeolite-Catalyzed Benzene Methylation in ZSM-5. ACS Catal. 2013, 3 (11), 2556-2567.

(146) Vos, A. M.; Schoonheydt, R. A.; De Proft, F.; Geerlings, P. DFT Study on the Electrophilic Aromatic Substitution Catalyzed by Lewis Acids. J. Catal. 2003, 220 (2), 333-346.

(147) Macht, J.; Carr, R. T.; Iglesia, E. Consequences of Acid Strength for Isomerization and Elimination Catalysis on Solid Acids. J. Am. Chem. Soc. 2009, 131 (18), 6554-6565.

(148) Fang, H.; Zheng, A.; Xu, J.; Li, S.; Chu, Y.; Chen, L.; Deng, F. Theoretical Investigation of the Effects of the Zeolite Framework on the Stability of Carbenium Ions. J. Phys. Chem. C 2011, 115 (15), 7429-7439.

(149) Lesthaeghe, D.; Horré, A.; Waroquier, M.; Marin, G. B.; Van Speybroeck, V. Theoretical Insights on Methylbenzene Side-Chain Growth in ZSM-5 Zeolites for Methanol-to-Olefin Conversion. Chem. - Eur. J. 2009, 15 (41), 10803-10808.

(150) Olsbye, U.; Svelle, S.; Lillerud, K. P.; Wei, Z. H.; Chen, Y. Y.; Li, J. F.; Wang, J. G.; Fan, W. G. The Formation and Degradation of Active Species during Methanol Conversion over Protonated Zeotype Catalysts. Chem. Soc. Rev. 2015, 44 (20), 7155-7176.

(151) Mores, D.; Kornatowski, J.; Olsbye, U.; Weckhuysen, B. M. Coke Formation during the Methanol-to-Olefin Conversion: In Situ Microspectroscopy on Individual H-ZSM-5 Crystals with Different Brønsted Acidity. Chem. - Eur. J. 2011, 17 (10), 2874-2884.

(152) Janssens, T. V. W.; Svelle, S.; Olsbye, U. Kinetic Modeling of Deactivation Profiles in the Methanol-to-Hydrocarbons (MTH) Reaction: A Combined Autocatalytic-Hydrocarbon Pool Approach. J. Catal. 2013, 308, 122-130. 